\title{
EFFECTS OF RACISM AND DISCRIMINATION ON PERSONALITY DEVELOPMENT AMONG \\ AFRICAN AMERICAN MALE \\ REPEAT OFFENDERS
}

\author{
A Thesis \\ presented to \\ the Faculty of California State Polytechnic University, \\ San Luis Obispo \\ In Partial Fulfillment \\ of the Requirements for the Degree \\ Master of Science in Psychology \\ by \\ Tiffany Nicole Lockett \\ October 2013
}


(C) 2013

Tiffany Nicole Lockett

ALL RIGHTS RESERVED 
COMMITTEE MEMBERSHIP

TITLE:

Effects of Racism and Discrimination on Personality

Development among African American Male Repeat

Offenders

AUTHOR:

Tiffany Nicole Lockett

DATE SUBMITTED: October 2013

COMMITTEE CHAIR: Jennifer Teramoto Pedrotti, Ph.D.

Professor of Psychology \& Child Development

COMMITTEE MEMBER: Michael J. Selby, Ph.D.

Professor of Psychology \& Child Development

COMMITTEE MEMBER: Olga Dekhtyar, M.A.

Professor of Statistics 


\begin{abstract}
Effects of Racism and Discrimination on Personality Development among
\end{abstract}

African American Male Repeat Offenders

Tiffany Nicole Lockett

Throughout history in the United States, the African American community has consistently been the victim of social policies put in place to disenfranchise this population (Mauer \& Chesney-Lind, 2002; Painter, 2007; Parham, White \& Ajamu, 1999). With a longstanding presence of systemic racism and discrimination, the criminal justice system and the dominant culture continues to pathologize this minority group and advocate for increased penalties which further stigmatize African Americans, particularly males in this group (Reiman, 1996; Russell, 1998). Though most criminology research focuses on higher rates of criminal offending within the African American population as the result of the intersection of race, poverty, education, and employment (Russell, 1996), few studies take into account the potential effects that regular exposure to racial discrimination may have on this population. Even fewer take into account how one's experience with racism and discrimination may impact personality development.

The purpose of the study is to investigate a proposed causal link between racism and discrimination on criminal recidivism, using personality as an indirect variable to support this potential relationship. To do so, the study focuses on the criminal offending of an African American male population within a county probation system to explore how one's experience with racism and discrimination leads to the development of certain personality traits which then impact their criminal recidivism. As there is a significant dearth in the literature about the effects of racism and discrimination on this population, this study will provide a unique area of research on a population that has often fallen victim to deficit models in the field.

After exploring the traditional research about the unique experiences of the African American community as a whole, this study aims to provide another perspective as to why this population is disproportionately represented in the criminal justice system by accounting for the potential impact of individual experiences of racism and discrimination of African American males. A number of hypotheses have been generated to account for the interaction between racism, personality, and recidivism within the African American male offending population. It was hypothesized that self-reported experiences with racism and discrimination would lead to lower scored traits of warmth, self-control, and rule-consciousness and subsequently lead to higher rates of repeat offending; conversely, experiences with racism and discrimination would also lead to higher scored traits of dominance and vigilance which then would lead to higher rates of repeat offending. A path analysis will be conducted to elucidate potential links between these variables. Structural equation models found partial support for the hypotheses. Implications and future directions in this study are discussed.

Keywords: African American, racism, discrimination, microaggressions, recidivism, personality 


\section{ACKNOWLEDGMENTS}

I would like to extend my deepest gratitude to all those who helped with the generation of this Master's thesis. Thank you Dr. Teramoto Pedrotti for your role in chairing my committee and for your invaluable assistance throughout this process. Your unyielding patience and support have enhanced my research and writing skills, and for that I am truly grateful. Thank you Dr. Selby for your extensive knowledge in forensic psychology and your constant support over the past three years. Thank you Professor Dekhtyar for your statistical knowledge and education, especially in your willingness to go above and beyond so that I understood the statistics associated with this project. Thank you LaDonna Harris, Chief Probation Officer, John Keene, former Deputy Chief of Adult Services, and Lisa Abernathy for your assistance with supporting this research. Thank you Niculia Williams, Executive Director and to the staff of Berkeley Youth Alternatives for your assistance with this population and research project. Thank you Dr. Thomas Parham for inspiring me to look beyond the traditional scope of psychology and expanding my cultural knowledge of African American psychology. Thank you to my parents for all of your unconditional love and support through this journey; your prayers encouraged me in more ways than I can explain. Thank you Malcolm Turner for your assistance and support throughout this process. To all the young African American men who allowed me into your individual, unique experiences in this world, I thank you. 


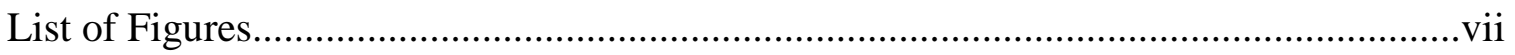

\section{CHAPTER}

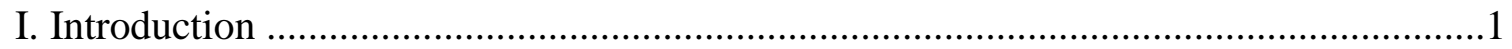

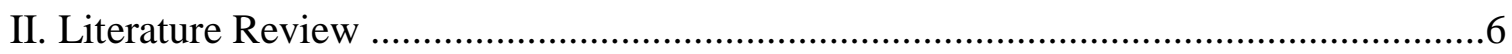

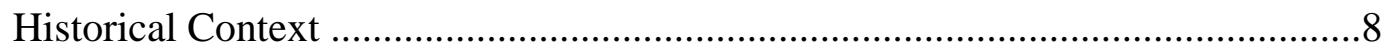

Current Context ………………………………………................................13

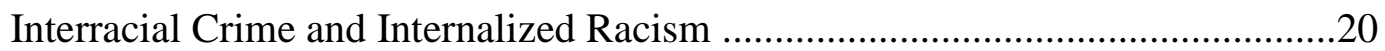

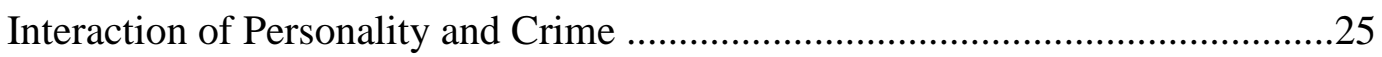

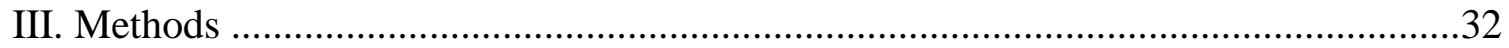

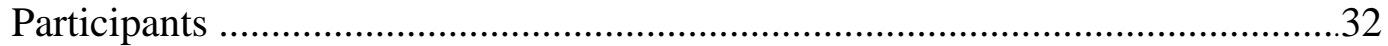

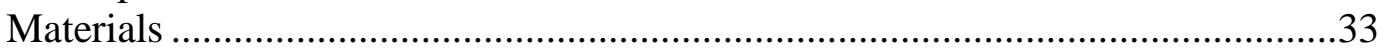

Personality Factors ..................................................................................33

Racism and Discrimination ...................................................................34

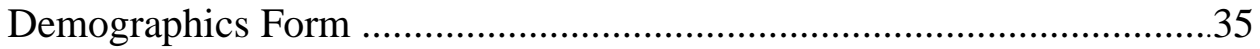

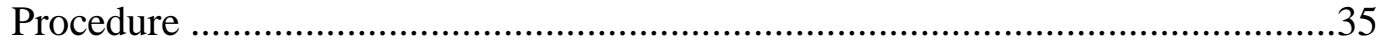

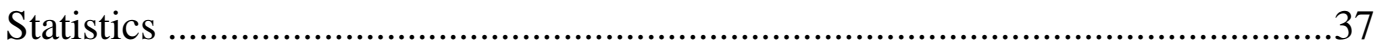

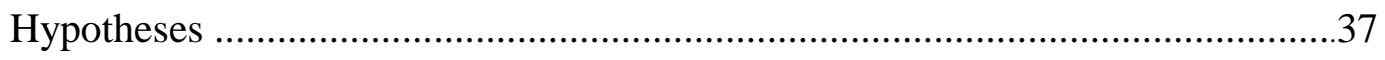

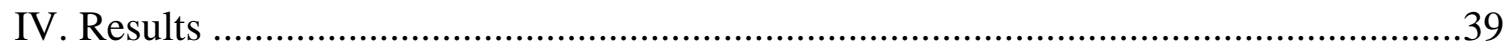

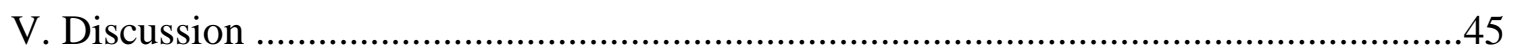

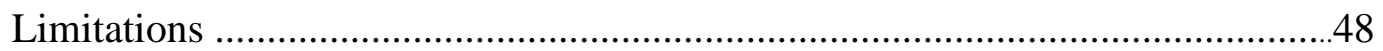

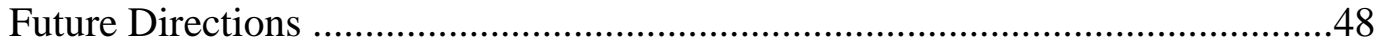

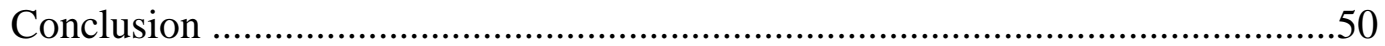

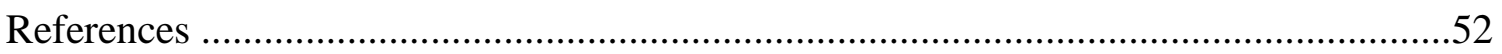

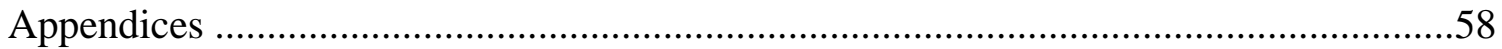

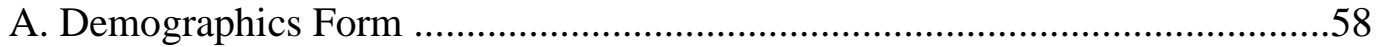

B. Survey for Participation .................................................................................

C. Inventory of Microaggressions against Black Individuals (IMABI) ...............60 


\section{LIST OF FIGURES}

Figure Page

1. Sue's Worldview Model ............................................................................... 24

2. Structural Equation Model: Warmth ........................................................... 40

3. Structural Equation Model: Dominance........................................................ 41

4. Structural Equation Model: Vigilance ......................................................... 42

5. Structural Equation Model: Rule-Consciousness .......................................... 43

6. Structural Equation Model: Self-Control …................................................... 44 
"Just as children were tracked into futures as doctors, scientists, engineers, word processors, and fast-food workers, there were also tracks for some children, predominately African American and male, that led to prison." (Ferguson, 2000, p.2.)

\section{CHAPTER I}

\section{Introduction}

Throughout the history of the United States, the dominant White culture has decided and controlled a social hierarchy that has been both overtly and covertly biased against the African American minority population (Parham, White, \& Ajamu, 1999). In today's technologically advanced society, media and technology heavily contribute to knowledge that shapes the general population's views. Because of their social influence and privilege, the dominant culture has the opportunity to tailor the exposure of the general population within the United States to maintain a sense of cultural homeostasis, i.e., where the dominant White culture is seen as superior in nature compared to the inferior messages displayed about other racial and ethnic minority populations. Historical nursery rhymes such as "If you're White, you're all right; if you're Brown, stick around; if you're Black, get back" and other similar messages are constantly illustrated through the dominant culture's choice of media programming. The influence of the media coupled with the longstanding cultural norms within the United States depict the African American population, in particular African American males, as hyperaggressive criminals (Akbar, 1981; Dixon, 2008; Painter, 2007; Parham et al., 1999).

Contemporary research about the general population points to the fact that the various environmental forms of racism that target African American males could, at least in part, explain the higher percentages of this population within the criminal justice system (Brewer \& Heitzeg, 2008; Brunson \& Miller, 2006; Dixon, 2008; Friedman, 
Lurigio, Greenleaf \& Albertson, 2004). For example, with the war on drugs campaign starting in the 1960s, people of color as a group, but specifically African Americans, were targeted for arrest on drug-related charges. Law enforcement agencies went into predominately Black neighborhoods with the sole intent to search for and arrest African Americans who were consuming drugs such as crack cocaine (Radosh, 2008). Moreover, criminal sentences for abusing crack cocaine were often grossly disproportionate to those given for use of powder cocaine, a form largely consumed by Whites. Not only did the African American presence in prison increase 217 percent from 1980-1993, but African Americans were incarcerated for longer sentences than their White counterparts during this time (Williams, 2010). The political attack on African American men continues to plague the African American community as a whole, and as a result may shift the beliefs of the dominant culture towards a worldview that criminalizes African American males. Where certain arguments suggest a strong likelihood that racism influences criminality (Mauer \& Chesney-Lind, 2002), there is a missing link regarding how racism interacts with personality factors. It is possible that an individual's experiences with racism and discrimination could lead to the development of certain individual characteristics, such as an increased likelihood to engage in maladaptive behaviors. Because of the increased racial discrimination experienced in this community, some African American individuals might respond to these negative messages about their racial and ethnic identities by developing certain personality traits in their young adult years that might in turn predispose them towards engaging in criminal activity.

In reviewing the current research, there appears to be a significant void related to the individual factors that may lead to criminal behavior (Russell, 1998). Indeed, there is 
evidence showing that one's social environment plays a substantial role in the development of hypervigilant and criminal behavior (Norris \& Kaniasty, 1992; Williams, Singh \& Singh, 1994). However, the question remains as to whether or not there is any correlation between an individual's personality (observed through traits such as vigilance) and their susceptibility to criminal activity. Of the available research, most arguments center around the belief that individuals who display personality traits such as high vigilance or low self-control are more likely to commit criminal behavior (Norris \& Kaniasty, 1992; Pratt \& Cullen, 2000). However, more information is needed about the intersection of personality and criminality both in general, and specifically within the African American population.

The potential effects of racism and other types of discrimination have not yet been fully studied related to understanding possible increased likelihood for criminality in this population. Moreover, there is minimal research focusing on the individual's perspective of his criminal behavior. Qualitative research as collected through interview or selfreported data could add significant information about how an individual's perspective is a direct result of his personality. Questions regarding reasons for engaging in a criminal act, history of criminal behavior (focusing on both crimes that did and did not lead to incarceration), experiences of racism and discrimination with law enforcement and/or experiences of discrimination from the general public once released on probation or parole, changes in experience with crime since his first criminal act, and most importantly factors that seem to have led to a decision to engage in criminal behavior may provide insight into this area of study. Finding answers to these questions can help to 
provide a unique point of view that integrates experiences with racism and discrimination and their personal stance on their criminal offending.

In the study at hand, the individual characteristics of African American men who have been incarcerated and have recently been released on probation will be explored to gain their individual perspectives on their own criminal behavior. Moreover, individual personality characteristics, family background, and more facets of their social demographics will be examined. There are three separate focus points which will provide a wide range of information about the individual experience: (a) experience with racism and/or discrimination, (b) personality testing, and (c) the demographic interview portion which will outline the individual's history with crime. Using these three foci, this research study will explore whether there is any relationship between one's experiences with racism and discrimination and subsequent personality development. Additionally, this research will explore whether certain patterns exist between specific personality traits as measured by the 16-PF (e.g., Warmth, Dominance, Vigilance, Rule-Consciousness, and Self-Control; Cattell, Cattell \& Cattell, 1993) and criminal activity, such as hypervigilance or excessive dominance.

To explore this causal relationship, a sample of previously incarcerated African American males on probation was recruited to complete self-reported measures exploring personal experiences with racism and discrimination, profile of personality, and demographic information. A structural equation model was generated to determine whether racism and discrimination act as a mediator between personality and recidivism in criminal activity. It was hypothesized that an individual's experience with racism and 
discrimination fosters the development of maladaptive personality traits that increase the likelihood and incidence that that same individual will commit a crime. 
"Being a Black man in America isn't easy. The hunt is on... and you're the prey!" (Hughes \& Hughes,1993).

\section{CHAPTER II}

\section{Literature Review}

For centuries, the dominant United States culture has disenfranchised racial and ethnic minority populations (Mauer \& Chesney-Lind, 2002; Painter, 2007; Parham, et al., 1999). Specifically, the African American population has consistently been pathologized throughout U.S. history due to cultural, physical, psychological, and social differences and this has been generated from a legacy of systematic and institutional racism and discrimination. According to Painter (2007), White supremacists responded to the minimal educational and economic gains of African Americans after the Reconstruction period using a number of means such as voter disenfranchisement, legalized Jim Crow segregation, and physical brutality through "extralegal executions" (p. 180) or lynchings.

As a result, these pathologizing norms have generated a foundation of stigma of inferiority, criminality, and limited possibilities for African Americans (Parham et al., 1999). Of these normed beliefs, the most damaging could be the association of African Americans with an increased likelihood for criminality. In some ways, the U.S. culture has historically and currently become anesthetized towards the African American criminal, i.e., unjustly labeling African American people as typical perpetrators of violence. In other words, it is expected that the perpetrators of criminal behavior would be African American, and often specifically a young male, such as in the recent case of Trayvon Martin. In addition, when criminal behavior is seen as normative in African American populations, little to no positive prevention efforts occur, while at the same time the response to this crime often involves harsher treatment, sentencing, and therefore 
continues the cyclical nature of these associations (Reiman, 1996; Russell, 1998). As a result of these disproportionate experiences within the African American community, Painter (2007) stated that "in cultural terms, the prevalence of incarceration has made jail part of the symbolism of black masculinity" (p. 384); therefore, the constant experience of excessive labeling and criminality among this population has almost led to a romanticized belief about imprisonment among African Americans and perpetuated throughout the media.. The constant exposure to racism and stereotyping towards this community affects individuals differently. In some cases, responses to such discrimination could be observed in maladaptive decision making in the form of criminal activity.

Existing research focuses more often on the social demographics of high crime neighborhoods, often concluding that low socioeconomic status, racial minority backgrounds, and other socio-individual factors such as single-parent households coincide, leading naturally to higher susceptibility of criminal activity (Wright \& Younts, 2009). In reviewing the current research on the African American population, there exists a void related to the individual factors that may lead to criminal behavior. While there is evidence showing that one's social environment plays a substantial role in the development of hypervigilance and criminal behavior (Akbar, 1981; Painter, 2007; Russell, 1998), there is little to no information about other factors that may influence one's likelihood towards crime. In many personal accounts, racism and discrimination permeate the experiences of being African American, and these subsequently affect African Americans' experience in the dominant culture. Specifically, African American males often internalize these racist beliefs aimed against them, and thus are plagued by 
the stereotypic, though false, belief that their race and gender predispose them towards criminality (Saucier, Hockett, Zanotti \& Heffel, 2010).

The focus of this research will explore three specific areas that illuminate the aforementioned unique experiences of African American males within the criminal justice system in the United States. First, a detailed review of the historical effects of racism and discrimination will explore how these constructs have permeated the African American experience through constant forms of disenfranchisement. Second, the current effects of the dominant culture perpetuate racism and discrimination in the forms of high incarceration rates, policing, and media influences. In accounting for both the historical and current contexts, there is evidence related to the effects of racism and discrimination on the African American community as a whole. However, there appears to be a lack of information regarding how these experiences personally influence the individuals within the African American community towards criminal behavior. To account for this concept, research exploring the psychological factors that impact African American male criminal offending will be explored. Using the framework of personality, the existing literature could reveal a potential cyclical relationship between personality and criminal offending, taking into account how the effects of racism and discrimination play an integral part in this relationship.

\section{Historical Context}

Racism and discrimination have been sociocultural constructs present throughout the United States for multiple generations. The dominant social majority maintains the hierarchal power to shape and define what they deem an "inferior population" as seen with any other opposing cultural group; this can be observed with the emergence of 
slavery and the African American minority (Painter, 2007). The earliest and most visible form of historical racism was an easily distinguishable difference based on darker skin tones or any biological likeness to African Americans. In the United States due to the established power structure, the dominant White culture determines which racial and ethnic minority group(s) will be marginalized. Wacquant (2002) attempts to reassess the "taboo" race question with respect to the U.S., arguing that African Americans have been "defined, confined, and controlled throughout the United States' history through a number of "peculiar institutions'" (p. 41); these include chattel slavery, Jim Crow segregation, the ghetto, and the prison. Each have continued to weaken the African American community and the outward appearance of this community as a whole. Throughout our country's history, the institution of racism has perpetually disenfranchised and dehumanized the African American population (Mauer \& ChesneyLind, 2002; Painter, 2007).

Painter (2007) describes slavery as a "dehumanizing institution" (p. 98) that not only lead to the physical trauma of multiple generations of African Americans, but also developed into psychological trauma through the vicarious learning of the slave experience based on the historical and vivid accounts of the older generations. With slavery, the establishment of hierarchal difference centered on race-based classifications between Black and White while labeling African Americans as inferior, inhumane, worthless, and as property. Despite the abolishment of slavery with the 13th Amendment, the victimization of African Americans continued as supremacists in the dominant White culture implemented a variety of means to restore power over African Americans through violence, social, and political policies (Painter, 2007). African Americans were further 
exploited for nearly a century with tenets of legally enforced racism and discrimination, such as Jim Crow segregation (Mauer \& Chesney-Lind, 2002; Russell, 1998). The ghetto (i.e. overpopulated, dilapidated neighborhoods plagued with crime and disease) arose in response to legalized segregation, strengthened by the large migration of African Americans to Northern states in hopes of finding lands of opportunity; this opportunity never came to fruition and the ghetto represented yet another blatant form of separation and subordination of African Americans because they were unable to live elsewhere as a result of both economically- and socially-enforced segregation. Riots within these ghetto communities furthered anti-Black sentiment, reinforcing the dominant belief that African Americans were excessively violent. Moreover, these riots quickly led to the demise of property and increase of negative stigma attached to these African American dominant neighborhoods. Wacquant (2002) asserts that the institutions of slavery, Jim Crow segregation, and the creation of the ghetto served two purposes: (a) the obtaining of labor from the African American community, and (b) the enacting of social ostracism that deems the African American population inassimilable as a separate class of individuals. Further, African Americans were unable to assimilate into the dominant culture based on three specific limitations: (a) their classification as property in a land that represented freedom, (b) the lack of the right to vote, and (c) their placement on the bottom of the United States social hierarchy (Wacquant, 2002). Not only did these three institutions further the abuse of African Americans in the labor and social arenas, but they also acted as what Wacquant called "race-making institutions," (p. 55) which continue the subordination of African Americans through symbolic and physical hierarchal differences for White Americans. 
The fourth institution that separated African Americans from White Americans in terms of treatment and norms was the prison, and this furthered the realm of social ostracism while at the same time not carrying the same significance for economic gain through labor extraction. Wacquant (2002) classifies the prison as "a carceral continuum" (p. 52) where today's ghetto neighborhoods now act as a gateway for the prison system. The prison furthers anti-African American sentiment by forcing prisoners into ethnically homogenous populations, forcing large numbers of African American males to develop within institutions that ostracize and stigmatize them. Wacquant (2002) characterizes the prison system's hold on African American males as an "ethnoracial control” (p. 50) via four elements: (a) stigma, (b) constraint (i.e. a racially and/or ethnically homogenous population created by the distinct space given to these incarcerated men within the prison), (c) territorial confinement (i.e. the extension of the space constraint outside the prison), and (d) institutional encasement (i.e. the dependency of the subordinate group based on their isolation from the dominant group and subsequent "style of life and social strategies" (p. 50) afforded to them. Plainly, Wacquant's concept of ethnoracial control is based on the dominant group's ability to ostracize and abuse the minority group through a cyclical pattern of subordination based on the social structures. The last three all represent the physical aspects of incarceration, which are then enhanced by the stereotype of excessive criminality within this population regardless of whether or not crimes have been committed. Largely due to racism at the core of the United States judicial system, the disproportionate numbers of African Americans in the prison system represent a more current example of the historical segregation of African Americans from the dominant society (Painter, 2007; Wacquant, 2002). 
Brewer and Heitzeg (2008) speculate that there has been a noticeable shift in crime and punishment in the United States justice system in an attempt to maintain control over the African American community. Despite the end of legalized racism such as Jim Crow segregation, racial and ethnic minorities, and African Americans in particular, continue to experience racial discrimination through being subject to "unequal protection of the laws, excessive surveillance, extreme segregation, and neo-slave labor via incarceration, all in the name of crime control" (Wacquant, 2002, p. 626). Moreover, the African American community continues to be bombarded by the legal impact of racism in modern society, including as harsher sentencing and police treatment for African Americans at least partially due to the practice of racial profiling. Edwin Sutherland and Donald Cressey (1974) concluded after reviewing several studies at that time that "African -Americans are more likely to be arrested, indicted, convicted, ad committed to an institution than are whites who commit the same offenses" (p. 133). Today, reports still show that the police appear to continue to target African Americans, putting into application the de facto racism that continues to label this population as criminal (Brunson \& Miller, 2006; Friedman, Lurgio, Greenleaf, \& Albertson, 2004; Mauer \& Chesney-Lind, 2002; Reiman, 1996). Mauer and Chesney-Lind (2002) state that not only is this community impacted by the vast and disproportionate numbers of individuals in this population either incarcerated or under correctional supervision, but the African American community also suffers from "invisible punishments" (p. 1) or further political, economic, and social penalties that result from their involvement with the system. 
Additional consequences such as felony disenfranchisement (Painter, 2007), or laws put in place to remove privileges for individuals who have been convicted of a felony crime, hinder the opportunities of convicted felons. Examples of this disenfranchisement include the inability of convicted felons to vote, hold public office, or bear arms (Brewer \& Heitzeg, 2008; Mauer \& Chesney-Lind, 2002). While these bans are universal to all convicted felons, the disproportionate numbers of African Americans convicted of felony crimes often leads to significant decreases in opportunities in these ways after the individual has transitioned out of the prison system. As a result of felony disenfranchisement, felony convictions prevent almost 25\% of African American men from voting; additionally, felony drug convictions, most often observed within the African American offending population, can lead to inability to access government services such as public assistance, housing, and career assistance (Painter, 2007). Additionally, occupational bans for previous offenders such as an inability to work with children or law enforcement, as well as an employer's ease to checking criminal background continue to serve as invisible punishments for African American offenders at a greater rate than these effect the non-African American population in general (Brewer \& Heitzeg, 2008).

\section{Current Context}

Traditional research within the field of criminology focuses mostly on the social demographics of high criminal activity, often hypothesizing that individuals from poorer, racial minority neighborhoods have increased susceptibility to engage in violence (Gottfredson \& Hirschi, 1990; Pratt \& Cullen, 2000; Russell, 1998). In addition, African Americans are disproportionately represented in U.S. prisons today (Federal Bureau of 
Prisons, 2012). Though only $12.6 \%$ of the United States population is African American, this group represents $37.5 \%$ of the U.S. prison population; in comparison, their White American counterparts, who make up $72.4 \%$ of the U.S. population outside of prison, only represent 59\% of the U.S. prison population (Federal Bureau of Prisons, 2012; U.S. Census Bureau, 2012). The African American racial group also represents one of the highest percentages within the parole and probation subsystems of the criminal justice system, second only to Caucasians and higher than any other racial and ethnic minority group almost combined (U.S. Department of Justice, 2011). African American men are more than eight times more likely to be incarcerated than their White male counterparts (Roberts, 2004). More recent studies substantiate the claim that minority men are represented in disproportionate numbers within the criminal justice system (Burt, Simons \& Gibbons, 2012; Mooradian, 2010). These statistics demonstrate how the criminal justice system is biased towards the harsher punishment of African American males; despite the argument that racial minorities in general are targeted for criminality, it appears that African Americans as a whole experience higher rates of imprisonment than any other minority group concluding that there is likely some specific targeting of this community. With access to such statistics and overt racial discrimination in the criminal justice system, the dominant society then develops opinions of African Americans as criminal, without understanding the contextual, historical, and environmental influences, which increase the likelihood of being convicted at these alarming rates (Akbar, 1981; Parham et al., 1999; Wright \& Younts, 2009).

Another likely factor influencing the disproportionate African American male presence within United States' prisons is the nature of interactions with law enforcement. 
Brunson and Miller (2006) conclude that African American youth epitomize the "symbolic assailant" (i.e., the representation of a common criminal; p. 534) for law enforcement personnel. Therefore, the police tend to label African American youth as common criminals upon sight, which further adversely impacts the relationship between law enforcement and the African American community. The symbolic assailant label is in part demonstrated in the harsher police treatment towards these youth. Research has shown that African Americans receive harsher treatment from police interaction than any other racial group (Brunson \& Miller, 2006; Friedman et al., 2004; Mauer \& ChesneyLind, 2002). In a study on this topic, Friedman and colleagues found that in a sample of young African Americans who were stopped by the police, $73 \%$ of the young males in this group, and $45 \%$ of the young females, reported that these stops were without merit. In addition, these researchers found that, in comparison to other racial and ethnic groups, young African Americans were most likely to experience physical maltreatment during their contact with the police, which again suggests that this community is targeted more than other minority racial and ethnic groups.

Police action within low socioeconomic, racial and ethnic minority neighborhoods often results in adverse consequences to these communities. For example, police involvement in urban communities with higher African American percentages, often manifests as aggression and higher percentages of police misconduct in dealing with community members (Brunson \& Miller, 2006; Russell, 1998). Russell (1998) delineates between police harassment and police brutality, both of which are forms of police misconduct which constantly plague African American communities. Explaining police brutality as the use of excessive force and police harassment as both law-abiding and 
unlawful police action, Russell (1998) states that African American males often experience blurred lines between the two police practices. Russell (1998) also asserts that African American males have an "endless supply" (p. 33) of police harassment stories which can be observed in unfair stops, questioning, assault, public humiliation, and even as far as the use of derogatory language and labeling. With police action such as this, it is only logical that members of these communities experience great difficulty when it comes to trusting the police. Additionally, when called upon for service to these communities, a much slower response time for assistance is found within these communities (Brunson \& Miller, 2006). As a result, the common presence of hypervigilant police practices are viewed as a source of fear and distrust in these communities rather than instilling a sense of safety in law enforcement.

In Brunson and Miller's (2006) study about interactions between African American adolescents and law enforcement, the researchers found that young African American men often endure recurrent yet involuntary contact with the police, and experience more physical and brutal interactions with law enforcement. Through the use of unwarranted stops and searches, African American youths characterized these aggressive tactics as harassment based on their belief of the police's unfavorable suspicion about the criminal propensity of African American male youth (Brunson \& Miller, 2006; Mauer \& Chesney-Lind, 2002; Russell, 1998). Moreover, the researchers found that the "symbolic assailant" label was deeply ingrained within the dominant United States culture, and gender specific to African American males particularly in adolescence based on the qualitative accounts from the participants in the study (Brunson \& Miller, 2006, p. 548). Brunson and Miller (2006) concluded that due to the beliefs that 
African American males were presumed guilty and harsher police behavior was justified for this community in general, these messages of "African American male = assailant" become more embedded within society at large. Movies such as Menace II Society depict these negative stereotypes in some of their African American male character references by describing the young men in the movie as "America's nightmare: young, Black, and don't give a fuck." (Hughes \& Hughes, 1993). As previously mentioned, the characterization of the African American as criminal is rooted throughout United States culture. Without a challenge to these pathologizing norms, African American youth and communities will continue to be discriminated against by law enforcement and African American males, in particular, will bear the brunt of these racist historical practices of the justice system enforced by the police.

This image is further sustained by the media. Various media outlets portray a culturally-normative, yet distorted depiction of the African American male: criminal, poor, and unmotivated (Akbar, 1981). Today, popular news sources flood U.S. households with images of African Americans in poor economic neighborhoods steeped with criminal activity such as gang violence, murder, robbery, and many other examples of self-inflicted Black-on-Black crime. Unfortunately, these images are then developed into stereotypes that continue to shape the opinions and perspectives of the dominant population equating African American males with criminals (Akbar, 1981; Painter, 2007, Parham et al., 1999). Research has shown that African Americans are more likely shown performing criminal acts than their White counterparts in media programming; moreover, repeated exposure to these messages have often led to social constructs which link African Americans with criminality (Dixon \& Azocar, 2007). Based on the results from 
their study, Dixon and Azocar (2007) found that "exposure to racialized crime news shapes perceptions of Blacks and race relations and leads viewers to see criminal activity as a Black activity" (p. 245). Hence, the negative depictions of African Americans that have existed throughout the past century have led to a harmful and long-lasting stigma against African American communities. This conceptualization continues to shape and strengthen the viewpoints and beliefs that have historically and currently pathologized African Americans.

In a study to examine the effects of negative overexposure of African Americans in the media, Dixon (2008) researched the impact of local news on attention to crime news and news trust in the prediction of African Americans and crime. Study results found that attention to crime news was positively associated with harsher guilt for African American perpetrators and suspects compared to White suspects (Dixon, 2008). There are several possible explanations for these associations; the core of which could be explained as covert racism. Dixon (2008) believes that "News viewing may be part of a process that makes the construct or cognitive linkage between Blacks and criminality frequently activated and therefore chronically accessible" (p. 107). Because of this chronic accessibility, those with heavy access to media and television news develop what Dixon (2008) calls a "Black criminal schema" (p. 107) when formulating his or her opinions about race and crime. It is because of these schemas that individuals with heavy local media consumption where African Americans are overrepresented as criminals would overgeneralize African Americans as violent.

The recent murder of Trayvon Martin, an unarmed 17-year-old African American male, exemplifies this very dynamic. Viewed as a threat due to his racial identity and 
style of dress, he was unfairly and without just cause targeted and murdered by George Zimmerman, a Latino male who claimed he felt threatened by Martin's presence in his neighborhood although he pursued and shot this young African American male (Botelho, 2012). Because of the systematic devaluation of African American males, mainstream media chose to focus on Martin's attire instead of the fact that Zimmerman profiled and murdered an unarmed African American teenager. In doing so, the dominant culture supported Zimmerman's right to defend himself against a "suspicious" African American male. To date, Zimmerman has been protected by the 'Stand your Ground' laws in his home state of Florida, which deem it acceptable to use any means necessary in selfdefense (Jonsson, 2012). The support for Zimmerman shows the ingrained racism in the dominant United States society by labeling Martin as a dangerous threat solely due to his race.

The above case of Trayvon Martin depicts another example of the pathologized African American culture which undoubtedly impacts the decision-making and worldviews of both the dominant White culture and African American populations. Additionally, Mercer, Ziegler-Hill, Wallace, \& Hayes (2011) conclude that the African American experience with racial discrimination has taken a turn towards more covert forms of racism. Researchers suggest that the dominant culture has modernized the stigmas about African Americans using racial microaggressions, or "brief, everyday exchanges that send denigrating messages to people of color because they belong to a racial minority group" (Sue et al., 2007, p.273). By using racial microaggressions, the dominant culture continues to target this community leading to further emotional distress among the population. Whether through the judicial system, policing strategies, or media 
influences, the perpetual disenfranchisement of African-Americans by the dominant culture continues to adversely impact this community. Although some acts of overt racism may no longer be legal, the longstanding effects of the aforementioned practices and continuous use of racial microaggressions continues to disparage African Americans within the United States population.

\section{Interracial Crime and Internalized Racism}

The Trayvon Martin case represents one of the most recent public, though not unique, examples of interracial crime. Saucier and colleagues (2010) studied the effects of racism on the perceptions and punishment of both interracial and intraracial crime in the United States to investigate the connection between the dominant culture's views of crime and racism. For the most part, the researchers examined hate crimes driven by racial prejudice. In a mock trial study to examine this connection, Saucier, Hockett, and Wallenberg (2008) found that crimes by Whites against African Americans are given less severe sentencing than crimes with African American perpetrators against White American victims are given more severe sentencing. In addition, Saucier and colleagues (2008) found that African Americans were given disproportionately longer sentences when assaulting White targets opposed to the sentences when assaulting same race (i.e., African American) targets. Finally, Saucier et al. (2008) found that individuals with higher racism believed that crimes with African American perpetrators and White victims should be given more severe punishment opposed to hate crimes with White perpetrators/Black victims and intraracial Black crime.

These research findings concluded that the individual's level of racism influences their perception and response to crime, in particular the severity of the crime, length of 
sentencing, and suggested harsher punishment, all of which is based on the race of the perpetrators and victim (Saucier et al., 2010). Put plainly, the effects of racism permeate the views of interracial crime while intraracial crime within the African American community is not a point of concern (Brewer \& Heitzeg, 2008; Reiman, 1996; Russell, 1998). This may affect an African American male's understanding of his worth in society (i.e., a low level of worth) and the disinterest in his criminal behavior if it is not carried out toward a White population. As a result, these messages of low self worth from the dominant culture in turn generates messages of inferiority and a devalued sense of culture which may then be manifested by an increase of intraracial crime within the African American community. As a consequence of constant bombardment of these negative messages about the self, some African Americans may internalize this devalued view of self. Bryant (2011) defines this internalized racism as the acceptance by some African Americans of the dominant culture's belief that places African Americans at the bottom of the social hierarchy combined with the acceptance of the pathologizing stereotypes about their abilities and inherent value.

Due to the overt and covert messages of devalued African American life, internalized racism, one of the least researched triggers of criminal susceptibility, is at an all time high (Bryant, 2011). In an attempt to account for the increasing rates of crime, Bryant (2011) hypothesized that internalized racism acts as a "distorted developmental pathway" (p. 693) that influences African American youth towards practicing antisocial behavior. The traditional risk factors for youth violence (e.g., low socioeconomic status, involvement with delinquent peers, and illicit substance use; Bryant, 2011) cannot explain the gross overrepresentation of African American males involved in the criminal 
justice system. It may also be that internalized racism leads some members of this group to see prison and a life of crime as more of a "destiny," because of the self-degradation caused by the acceptance of negative beliefs about African American worth and ability.

In his study looking at aggressive behavior in African American males, Bryant (2011) concluded that internalized racism was the most statistically significant variable with the largest effect size on the variable of aggressive behavior, followed by impulsivity, delinquent peers, and an aggressive response to shame. To examine the overall propensity for violence, the same study concluded that internalized racism again had the largest effect size, higher than impacts of delinquent peers, impulsivity, and/or substance use (Bryant, 2011). Although not a direct predictor of violent behavior in Bryant's study, internalized racism was shown to be a risk factor for many of the factors that suggest propensity toward violent behavior (e.g., aggressive behavior and attitude toward guns and violence). Bryant concludes that the negative self-worth inherently fostered by the dominant culture's standards of inferiority and criminality, therefore may have at least an indirect impact on engagement in violent crime within the African American community.

Bryant (2011) argues that youth violence in African American communities is currently at epidemic proportions, specifically in the form of intraracial crime. The rate of homicide within the African American community has drastically increased over the years specifically with African American perpetrators and victims, observed mostly with gun violence. Fox and Swatt (2008) found in the years 2002 until 2007, homicides involving African American young male victims increased by $31 \%$ and as perpetrators by 43\%. Similarly, the use of gun violence among the African American young male 
population has increased to $85 \%$, with an increase in Black male offenders 25 and older (Fox \& Swatt, 2008). Accounting for these increases, Fox and Swatt (2008) believe that internalized racism, i.e., "the acceptance of the hegemonic hierarchal stratification of race that places them at the bottom of the order" has led to the development of an "acceptance of negative stereotypes about African Americans concerning their abilities and intrinsic worth" (p. 692). In other words, the acceptance of these internalized messages about low self-worth has increased the susceptibility for violence and criminal activity within the community. If an African American male is lacking in self-respect and fosters negativity towards his own race, he could potentially develop an inclination to engage in intraracial violence (Fox \& Swatt, 2008).

As a result of these negative messages, there is a possibility that the worldview of these African American males is then shifted towards negativity. In Sue's (1978) worldview model (see Figure 1), Sue believes that an individual's worldview is based on an internal-external continuum of control and responsibility (Mio, Barker, \& Tumambing, 2009). With this model, it appears that African American males are often characterized as having an external locus of control and external locus of responsibility; these males have little to no control over their own lives and also believe that the dominant society is not in favor of their success. People identified in this quadrant experience a worldview that is tainted to the point that they stop trying in life and believe they are powerless to change (Sue, 1978). Due to their longstanding history and experience with racism, the African American community has learned to expect that the dominant society will continue to hinder their success and deprive them of upward mobility. 
Figure 1. Sue's Worldview Model (1978)

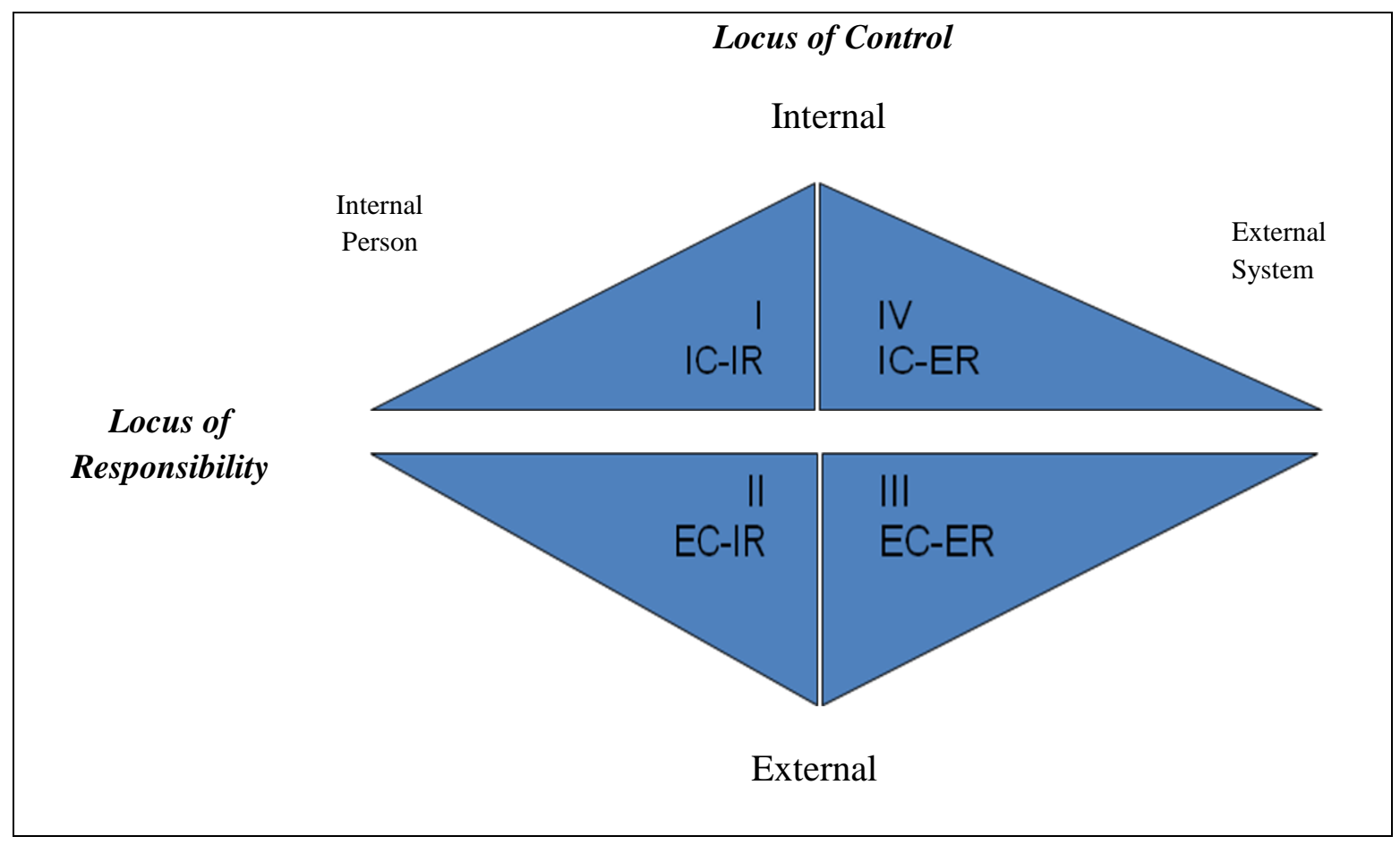

Because of this tainted worldview, many African American males might resort to criminal activity because their life experiences have falsely led them to believe that they lack the self-control to refrain from maladaptive behaviors. Due to the perpetual messages of being powerless, one could hypothesize that engaging in criminal activity would be one way that individuals with an external locus of control and external locus of responsibility would try to regain some control over their lives from the dominant society. Moreover, the message of gaining self-control could evolve into a cultural norm. Painter (2007) states that the commonness of incarceration has led to a cultural symbolism in that jail equates to masculinity within the African American community. Movies such as "Juice" illustrate this symbolic masculinity within these communities by referring to power and manliness as "the juice," where character Bishop exhorts that to 
gain respect in this world, young Black men "gotta be ready to throw down, stand up, and die for that shit" (Heyman et al., \& Dickerson, 1992). Rather than allowing the dominant culture to define their worldview and life experiences, many members of the African American community have developed their own attempts to experience power in a society that deems them powerless. Instead of placing all the blame on racist policies and structures, it is important to acknowledge how racism affects the individual and how it manifests on the continuum of responsibility and control.

\section{Interaction of Personality and Crime}

Traditional research about African Americans has shifted several times with foci on inferiority, deprivations and deficits, and the development of a modern multicultural approach to viewing African Americans (Parham et al., 1999). Two types of models generated to explain difficulties within the African American community as a whole have historically existed within the literature: those that center on African American "inferiority" and those that center on deficits and deficiencies that exist within this community at large (Parham et al., 1999). Inferiority models assert plainly that African Americans are inferior to Whites and internalize any difficulties from this population on African American individuals themselves. Deficit-deficiency models state that problems also exist in the African American community due to deficient intelligence, cognitions, and family structure and their differences from the dominant White middle class norms (Parham et al., 1999). At present, there is a significant dearth in the literature surrounding the intersection of personality and criminal behavior in general. There is even less literature related to these facets within the African American adult population, as most of the existing literature focuses on majority racial groups. Additionally, most of the 
research that does focus on African Americans focuses on the response to crime as a result of the stereotypic notions that crime remains solely a predominant issue within racial and ethnic minority communities (Painter, 2007).

Williams, Singh, and Singh (1994) studied the impact of perceived crime on defensive actions of urban youth. Their study found that urban adults fear leaving their homes or immediate neighborhoods at night and use defensive measures such as carrying weapons to guarantee their safety. To protect themselves from the criminal susceptibility of their own environments, urban adults were more likely to remain home or use weapons such as guns, knives, and mace to defend themselves if faced with criminal activity. Moreover, the same study found that a large percentage of these adults have received self-defense training to protect themselves from being victimized. To explain this increase in self-defense, Williams and colleagues (1994) hypothesized that crime prevention at the national level has changed from solving the core circumstances of crime such as discrimination, economic deficiency, and unemployment to individual actions to reduce their exposure to crime. Simply, racial and ethnic minority adult populations cannot rely on the governmental and social systems put in place for their protection and instead have become self-sufficient and vigilant with their personal defense (Brunson \& Miller, 2006). In communities with high rates of crime, individuals are more likely to protect themselves rather than count on police protection.

According to Sue (2010), many marginalized populations develop a "healthy paranoia or cultural mistrust" (p. 73) towards the dominant culture based on their experience with racism and discrimination. Therefore, these groups become inherently suspicious of the motives of the dominant culture (i.e. African American communities 
becoming more suspicious about the presence of the police or lack thereof). Sue (2010) believes that healthy paranoia serves a number of critical functions for the marginalized communities, most notably that such paranoia "may lead to functional and adaptive mechanisms to deal with the slights, invalidations, and insults that are delivered" (p.74). For that reason, it would make sense that the minority African Americans communities would demonstrate more vigilance and self-defense, especially since their interactions with the police were found to be less than favorable.

Norris and Kaniasty (1992) similarly observed how self-help prevention strategies and personal vigilance increased in response to criminal activity within minority urban communities. In their study, Norris and Kaniasty (1992) studied four areas of precaution including: vigilance; the use of locks; neighbors; and public and private professionals to examine public safety and psychological distress resulting from fear of crime. Vigilance, a personality factor measured in this study, was defined as "an attempt to protect one's personal safety by means of heightened alertness or awareness of crime" (Norris \& Kaniasty, 1992, p. 628). Results from this study showed that racial and ethnic minority populations, in particular, were more likely to use vigilance in their response to being victims of crime, and are also more likely to develop this coping strategy due to their increased exposure to crime in their impoverished neighborhoods. Despite their heightened vigilance, there was little to no effect on the prevention of crime in these neighborhoods (Norris and Kaniasty, 1992). One of the interesting conclusions within Norris and Kaniasty's study was that fear of crime was found to be a significant predictor of ensuing crime. In other words, "fear increases risk more than precaution decreases risk" for committing criminal acts (Norris \& Kaniasty, 1992, p. 645). To protect oneself 
from being victimized by crime, these individuals often develop hypervigilance, so much so that in their attempts to protect themselves, they become increasingly violent to deter other's from targeting them (Norris \& Kaniasty, 1992). Therefore, it is important to observe how racial and ethnic minority populations respond to their developed psychological distress with regards to crime.

Self-control, another personality factor, also relates to one's susceptibility to engage in criminal behavior. In their meta-analysis, Pratt and Cullen (2000) discovered that low self-control is '"one of the strongest known correlates of crime" (p. 952). Selfcontrol, according to Gottfredson and Hirschi (1990), is developed in early childhood due to parent socialization, which particularly affects an individual during adolescence. Hay and Forrest (2006) stated that low self-control is caused by poor parental socialization, specifically a lack of parental monitoring and recognition of deviance in the moment. Parents' active involvement in their child's life and monitoring of their behaviors does in fact impact the child's developed self-control and decreases the likelihood they will commit crime (Hay \& Forrest, 2006).

Many African American families are often disenfranchised through a number of means most often linked to finances. African American families are disproportionately impacted by social policies at each level of social administration and are met with numerous obstacles preventing access to social services (Parham et al., 1999). To address these problems, often times, young African American children are labeled "latchkey kids" who become much more independent in that these youths are more self-reliant when at home after school. As a result, these latchkey children have little to no parental monitoring, one of the factors that influences the development of self-control. Without 
this monitoring and recognition of deviance by parents, young African American children are more at-risk for low self-control. Mitchell and MacKenzie (2006) believe that schooling is another important measure of self-control. In communities with dilapidated school systems, self-control will likely waver and mimic the same negative responses indicated with poor parental monitoring. Poor school systems have a major impact on the self-control of these African American students. With poor monitoring and poor resources in his education, African American males could be more likely to experience poor self-control coupled with more negativity towards themselves as a result of such a limited life experience; as a result, an African American teenager could develop an inclination to engage in criminal activity.

Specific to the criminal population, Hirschi and Gottfredson (2001) believe that criminal justice interventions to reduce criminality in repeat offenders are unlikely to be effective. Specifically, they maintain the belief that "because low self-control arises in the absence of the powerful inhibiting forces of early childhood, it is highly resistant to the less powerful inhibiting forces of later life, especially the relatively weak forces of the criminal justice system" (Gottfredson \& Hirschi, 1990, p. 255). However, these general views of self-control do not inherently apply to the African American community. As mentioned earlier, this community experiences extremely low self-control as a result of the consistent lack of control over their own experiences perpetuated by institutionalized racism and illustrated in Sue's (1978) Worldview Model. Therefore, regardless of parental involvement or schooling, the structural hierarchy put in place inhibits the development of self-control within these youth, potentially leading to criminality. To examine how self-control changes, Mitchell and MacKenzie (2006) found that 
imprisonment increases egocentricity and problems related to controlling one's temper likely due to confinement and lack of privacy. Moreover, this population also relayed fears about their safety and 70\% reported being victimized in some capacity (Mitchell \& MacKenzie, 2006). All in all, Mitchell and MacKenzie (2006) found that self-control is in fact affected by one's social context, which could explain how self-control is in fact impacted by one's experience with racism and discrimination. To combat some of these negative experiences and susceptibility to criminality, Hirschi and Gottfredson (2001) believe that early intervention in childhood offers the greatest effort to combat crime. Therefore, without the successful early involvement of parents, schools or even neighborhood to protect these young people from experiencing racism and discrimination, those individuals who continue to experience racism and discrimination will continue to experience diminished self-control and are more likely to engage in perpetual criminal offending

As a result of the experiences with racism and discrimination perpetuated by the dominant culture, it could be suggested that young African American males are more susceptible to imprisonment and criminal reoffending. This study will attempt to observe whether or not such discrimination affects criminal offending using a personality lens. In other words, do repeat offenders display different personality traits as a result of their subordination from the dominant culture? To observe this, this study will implement a number of measures that focus on demographics, personality, and experiences with racism. Therefore, this study will show the psychological effects of racism and discrimination through criminal behavior in an attempt to provide another explanation for 
criminal offending outside of socioeconomic status, minority background, and additional social factors. 


\section{CHAPTER III}

\section{Methods}

\section{Participants}

Participants in this study were 80 African American males ranging from 18 to 25 years of age living in the Bay Area with the average age of participants being 21.09 years $(S D=2.29)$. All of the participants in the study identified as African American or Black (100\%). To qualify for this study, each participant had to be actively serving a probation sentence after being convicted of a misdemeanor or felony offense. These participants have served at least one period of incarceration within either the county jail or state prison. Participants were acquired through the county's department of Adult Probation based in the Bay Area in the state of California. Participation in this study was voluntary and all efforts were made to ensure confidentiality during their involvement in the study. Participants were chosen based on their self-reported recidivism within the county probation system. First, the participants were selected using stratified sampling to diversify the sample to account for the different amounts of recidivism in the population. The strata included randomly sampling from each group to have an equal amount of participants in each group which accounted for recidivism (i.e. five different groups to account for the self-reported numbers of criminal offending ranging from one to five repeat offenses). From there, simple random sampling within the homogenous strata was used to generate the list of active participants. The sample included as much diversity as possible to strengthen the variety of the data.

All of the participants were currently serving probation terms with an average of 2.51 terms on probation; this equates to being incarcerated at least three times total 
$(S D=1.136)$. The majority $(n=62,77.5 \%)$ of this sample were arrested as juveniles and incarcerated in juvenile detention centers, whereas the other 18 participants $(22.5 \%)$ did not report being under juvenile probation in their criminal offending history. With regard to employment status, the majority $(n=66,82.5 \%)$ of the participants in the study identified as unemployed, while the other $14(17.5 \%)$ were employed at the time of their participation. Most of the participants $(n=50,62.5 \%)$ self-reported that they did not possess a high school diploma or GED; alternatively, 30 participants (37.5\%) reported being high school graduates.

\section{Materials}

\section{Personality Factors}

The Sixteen Personality Factor Inventory (16PF; Cattell, Cattell \& Cattell, 1993) was developed to identify and measure the principal features of personality using factor analysis of the various adjectives that describe human behavior in the English language. Now in its fifth edition, the 16PF uses more descriptive labels to identify both Individual Personality Factors (e.g., "Dominance") and Global Factors, the latter of which are comprised of groups of the individual factors (e.g., "Extraversion" includes Warmth, Liveliness, Social Boldness, Privateness, and Self-Reliance ). The 185-item inventory consists of 16 scales with 15 or more items centered around each individual personality factor. Each primary factor is scored based on a continuum of adjective responses ranging from low to high scores (e.g., low Vigilance described as "trusting, unsuspecting, and accepting" versus high Vigilance as "vigilant, suspicious, skeptical, and wary"). Additionally, the inventory evaluates an individual's social desirability with an Impression Management index. 
Responses to the items are generated using standardized ten, or sten scores, ranging from 1 to 10 with a mean of 5.5 and standard deviation of two (Russell \& Karol, 2002). Scores that fall between one and three are considered in the low range; scores between four and seven are considered average; scores from eight to ten are considered high range scores. The low and high score ranges indicate that the particular trait will be more perceptible in the respondent's behavior (Russell \& Karol, 2002). With the fifth edition of the 16PF, Cattell et al. (1993) improved their psychometrics with satisfactory internal reliability averaging at .76 (Cronbach's $\alpha$ ranging from .68 to .87). Additionally, test-retest reliability was also statistically significant both two weeks and two months after the initial inventory was taken (.80 and .70, respectively; Russell \& Karol, 2002).

\section{Racism and Discrimination}

The Inventory of Microaggressions Against Black Individuals (IMABI; Mercer, Ziegler-Hill, Wallace \& Hayes, 2011) was created to measure the racial microaggressions experienced by individuals who identify as African American or Black. In exploring these microaggressions, the measure focuses specifically on the microinsults and microinvalidations that African Americans experience in addition to the resulting distress experienced by this population. The IMABI measure provides a unique insight into the race related experiences of African Americans that current racism and discrimination measures did not account for with a significant focus on the subsequent stress experienced as a result of racist experiences (Mercer et al., 2011). The 14-item measure is based on seven dimensions of Sue and colleagues' (2007) categories of racial microaggressions including: (a) Ascription of Intelligence, (b) Assumption of Inferior Status/Second Class citizenship, (c) Pathologizing Cultural Values and Communication 
styles, (d) Assumption of Criminal Status, (e) Denial of Individual

Racism/Colorblindness, and (f) Myth of Meritocracy).

Responses to the measured items are based on a five-point Likert scale where a score of 0 means "This has never happened to me" and a score of 4 means "This event happened and I was extremely upset." All the items are scored in a positive direction so that low scores equate to minimal experiences with microaggressions and higher scores indicate more experiences with racial microaggressions. Mercer et al. (2011) showed strong psychometric properties for the IMABI with internal consistency of (Cronbach's $\alpha$ $=.94$ ) and a significant positive correlation with the 45 original items from the IMABI ( $r$ $=.98, p<.001)$.

\section{Demographics Form}

Participants in this study were asked to share their demographic information electronically, including race and ethnicity, gender, socioeconomic status, and other supplemental factors (See Appendix A). The demographic information also included a detailed outline of their criminal history including all involvement both within and outside the criminal justice system.

\section{Procedure}

Participants were recruited with brief surveys (See Appendix B) asking about their involvement with the criminal justice system. These surveys also included their perceptions of racism and discrimination as a result of being an African American male

navigating the probation system. Probation officers and community officials disseminated the surveys to probationers on their individual caseloads, and those willing to participate were then placed on a participation list. Participants were asked again if they were 
participating at their own desire instead of at the persuasion of their probation officer. Each participant was informed again that his participation in the study would not affect his probation sentence and reminded that if he no longer wanted to participate, he had the option to remove himself at any time from the research study.

After recruiting the participants, stratified sampling was used to select the participants based on their self-reported number of criminal offenses and reoffending. With stratified sampling, the participants were placed into groups based on the number of crimes they had committed; in doing so, this accounted for a diverse sample to represent recidivism within the model. From there, simple random sampling was used to select specific participants from the stratified lists to ensure an equal amount of participants will be used from each group, to collect variety within each sample. At this point, those interested were contacted by the researcher and individual meetings were scheduled to administer the 16PF, IMABI, and a brief qualitative interview about their experience. Demographic information (as described above) was reviewed at a separate time. At the onset of the meeting, the participants were given an informed consent document outlining the purpose of the research and provided their consent to the researcher. Participants were also informed of their right to discontinue their participation within the study at any time if they experience any intolerable discomfort associated with the study.

The entire participation took no longer than 60 minutes, including 35-40 minutes to complete the 16PF, 5 minutes for the IMABI, and an additional 10-15 minutes for a short interview. After their participation was completed, the participant was thanked for their cooperation and briefed about the purpose of the study. 


\section{Statistics}

To determine whether the participants' experiences with racism and discrimination have influenced specific personality traits, a structural equation model was generated using the responses from the IMABI as a mediating variable. The results from the IMABI represented racism and discrimination; these results mediated the effects of personality development and subsequently led to recidivism. The primary personality traits measured for this study were Warmth, Dominance, Vigilance, Rule-Consciousness, and the global factor measured will be Self-Control. Each of these traits from the 16PF along with recidivism as measured in their self-reported interview were entered as dependent variables. Using AMOS software to create a structural equation model, a potential causal relationship between personality and subsequent reoffending was explored. To explore the strength of the models, the following statistics were used to determine the strength of the relationships: discrepancy measures, RMSEA $(<0.05)$, comparative fit index $(>.90)$, and $\chi^{2}$-distribution (not significant) to determine the statistical significance of the model.

\section{Hypotheses}

After exploring the research about the unique experiences of the African American community as a whole, a number of hypotheses have been generated to account for the interaction between racism, personality, and recidivism within the African American male offending population. The hypotheses are as follows:

(a) Participants' experience with racism and discrimination (as measured by the IMABI) will lead to the development of low warmth resulting in increased incidences of repeat offending and incarceration. 
(b) Participants' experience with racism and discrimination (as measured by the IMABI) will lead to the development of excessive dominance resulting in increased incidences of repeat offending and incarceration.

(c) Participants' experience with racism and discrimination (as measured by the IMABI) will lead to the development of hypervigilance resulting in increased incidences of repeat offending.

(d) Participants' experience with racism and discrimination (as measured by the IMABI) will lead to the development of low rule-consciousness resulting in increased incidences of repeat offending.

(e) Participants' experience with racism and discrimination (as measured by the IMABI) will lead to the development of poor self-control resulting in increased incidences of repeat offending. 


\section{CHAPTER IV}

\section{Results}

Using path analysis, a series of structural equation models were constructed to explore a potential causal relationship between racism/discrimination, personality, and criminal reoffending. The total score generated by the Inventory of Microaggressions Against Black Individuals (IMABI; Mercer et al., 2011) was used as a mediating variable, whereby the scores for the measured personality traits (warmth, dominance, rule-consciousness, vigilance, and self-control) were entered as independent variables; the self-reported offending number was then entered as the dependent variable.

\section{$\left(H_{1}\right)$ Participants' experience with racism and discrimination will lead to the development of low warmth resulting in increased incidences of repeat offending and incarceration.}

To determine the effects of racism and discrimination on personality and subsequent offending, a structural equation model measuring the personality trait, warmth, was generated. Racism and discrimination negatively affected change in the trait warmth $\left(m_{1}=-.59\right)$ and warmth then subsequently negatively affected change in recidivism $\left(m_{2}=-.18\right)$. Negative regressions are largely due to the measured variable being lower scores for measuring the warmth personality trait. In reviewing the squared correlations, this model concludes that there is a weak relationship between racism and discrimination and the trait warmth $\left(r_{l}=.35\right)$; however, the model proposed that there is a stronger relationship between the warmth personality trait and recidivism $\left(r_{2=.} .75\right)$. Additionally, this model demonstrates that there is a direct relationship between racism and discrimination with recidivism $\left(r_{3}=.75\right)$ whereby the warmth personality trait 
indirectly affects this relationship. Statistical significance of the model varies depending on the measurements used. RMSEA (.77) and the $\chi^{2}$-distribution were significant (CMIN=.000) which concludes that this model was nonsignificant; however, the comparative field index was $>.90(\mathrm{CFI}=1.0)$ and that signifies some statistical significance in this model.

Figure 2. Structural Equation Model: Warmth

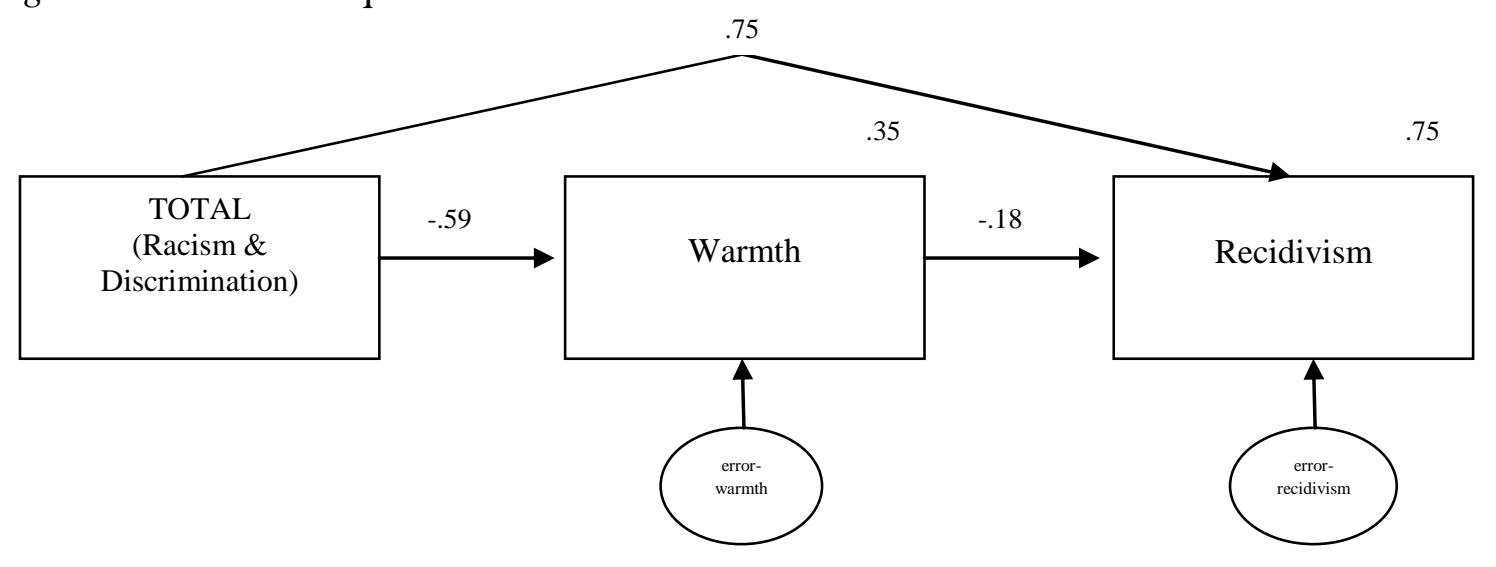

$\left(\mathrm{H}_{2}\right)$ Participants' experience with racism and discrimination will lead to the development of excessive dominance resulting in increased incidences of repeat offending and incarceration.

To determine the effects of racism and discrimination on personality and subsequent offending, a structural equation model measuring the personality trait, dominance, was generated. Racism and discrimination positively predicted change in the trait dominance $\left(m_{l}=.51\right)$ and dominance then subsequently predicted no change in recidivism $\left(m_{2}=.00\right)$. This model concludes that there is a weak relationship between racism and discrimination and the trait dominance $\left(r_{l}=.26\right)$ but a strong relationship between racism and discrimination and recidivism with dominance as an indirect mediating variable $\left(r_{2=} .74\right)$. Additionally, this model demonstrates that there is a direct 
relationship between racism and discrimination with recidivism $\left(r_{3}=.85\right)$ whereby the dominance personality trait indirectly affects this relationship. Statistical significance of the model varies depending on the measurements used. RMSEA (.73) and the $\chi^{2}-$ distribution were significant $(\mathrm{CMIN}=.000)$ which concludes that this model was nonsignificant; however, the comparative field index was $>.90(\mathrm{CFI}=1.0)$ and that concludes that there is some statistical significance in this model.

Figure 3. Structural Equation Model: Dominance

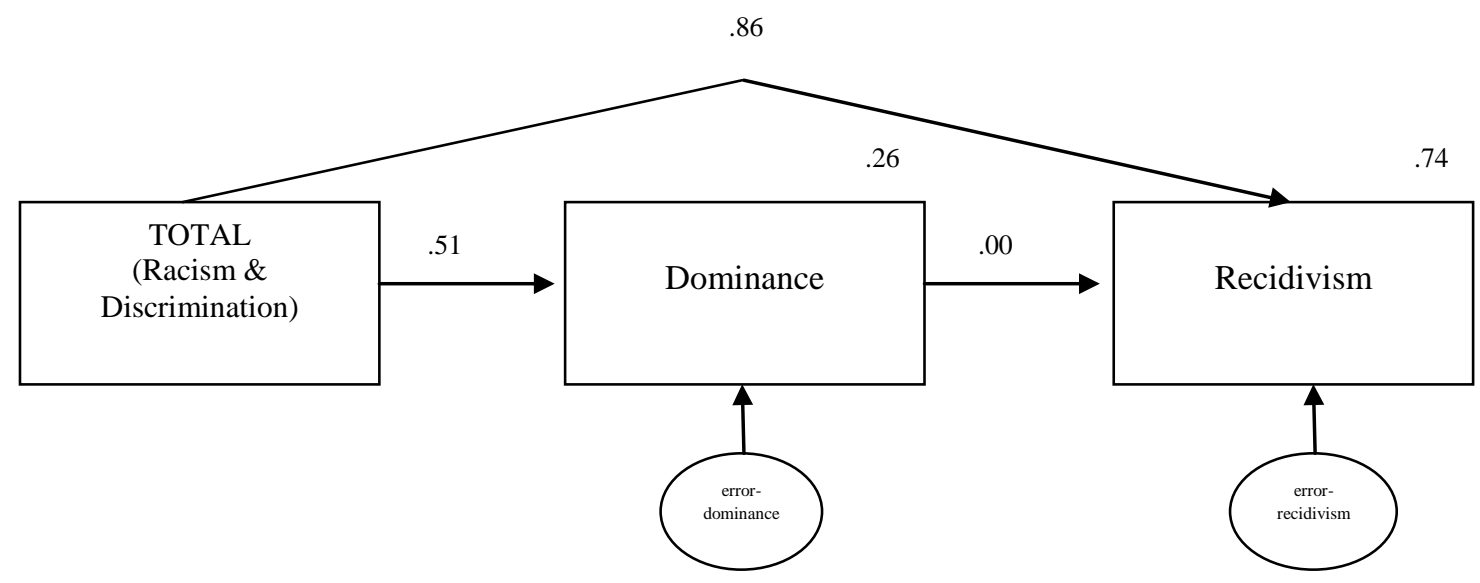

\section{$\left(\mathbf{H}_{3}\right)$ Participants' experience with racism and discrimination will lead to the development of hypervigilance resulting in increased incidences of repeat offending.}

To determine the effects of racism and discrimination on personality and subsequent offending, a structural equation model measuring the personality trait, vigilance, was generated. Racism and discrimination positively predicted change in the trait vigilance $\left(m_{l}=.33\right)$ but vigilance then subsequently predicted negative change in recidivism $\left(m_{2}=.-.03\right)$. This model concludes that there is a weak relationship between racism and discrimination and the trait vigilance $\left(r_{l}=.11\right)$ but a strong relationship between racism and discrimination and recidivism with vigilance as an indirect mediating 
variable $\left(r_{2=} .74\right)$. Therefore, the model measuring the vigilance personality trait was significant. Additionally, this model demonstrates that there is a strong direct relationship between racism and discrimination with recidivism $\left(r_{3}=.87\right)$ whereby the vigilance personality trait indirectly affects this relationship. Statistical significance of the model varies depending on the measurements used. RMSEA (.688) and the $\chi^{2}$-distribution were significant $(\mathrm{CMIN}=.000)$ which concludes that this model was nonsignificant; however, the comparative field index was $>.90(\mathrm{CFI}=1.0)$ and that argues some statistical significance in this model.

Figure 4. Structural Equation Model: Vigilance

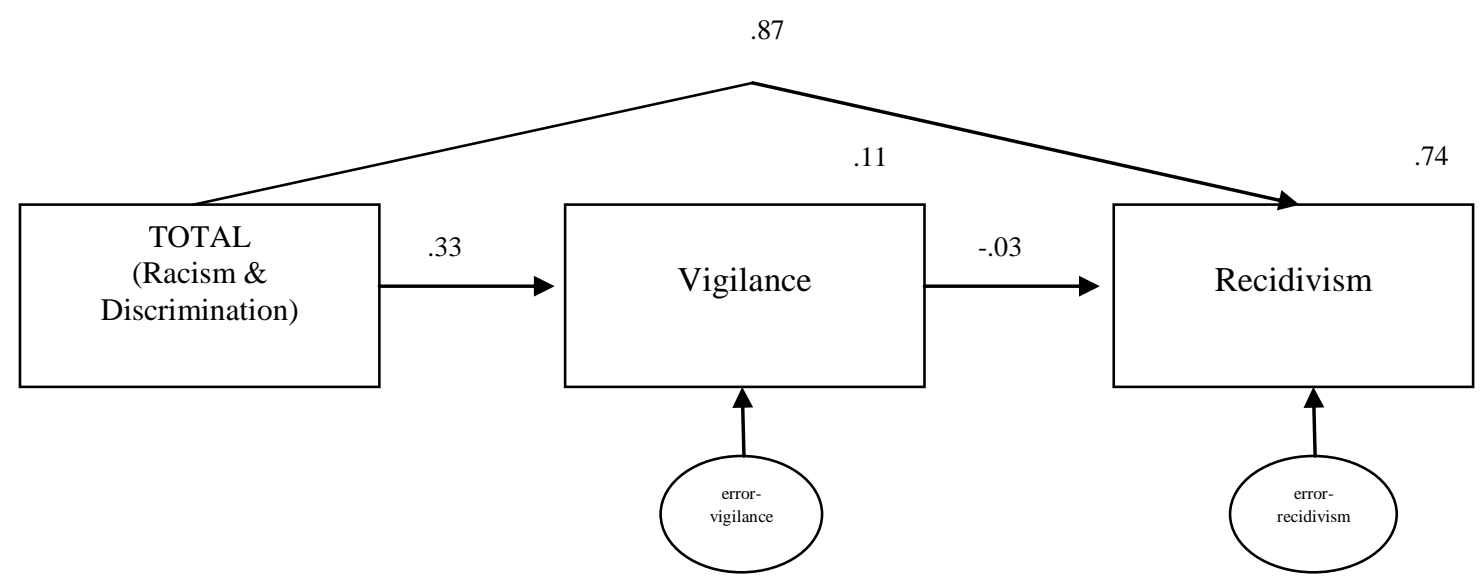

\section{$\left(\mathrm{H}_{4}\right)$ Participants' experience with racism and discrimination will lead to the}

\section{development of low rule-consciousness resulting in increased incidences of repeat}

offending.

To determine the effects of racism and discrimination on personality and subsequent offending, a structural equation model measuring the personality trait, ruleconsciousness, was generated. Racism and discrimination negatively predicted change in the trait rule-consciousness $\left(m_{1}=-.48\right)$ and rule-consciousness then subsequently 
negatively predicted change in recidivism $\left(m_{2}=-.07\right)$. This model concludes that there is a weak relationship between racism and discrimination and the trait rule-consciousness $\left(r_{l}=.23\right)$ but that there is a strong relationship between racism and discrimination and recidivism with rule-consciousness as an indirect mediating variable $\left(r_{2=.} .74\right)$.

Additionally, this model demonstrates that there is a direct relationship between racism and discrimination with recidivism $\left(r_{3}=.82\right)$ whereby the rule-consciousness personality trait indirectly affects this relationship. Statistical significance of the model varies depending on the measurements used. RMSEA (.72) and the $\chi^{2}$-distribution were significant $(\mathrm{CMIN}=.000)$ which concludes that this model was nonsignificant; however, the comparative field index was $>.90(\mathrm{CFI}=1.0)$ and that equates to some statistical significance in this model.

Figure 5. Structural Equation Model: Rule-Consciousness

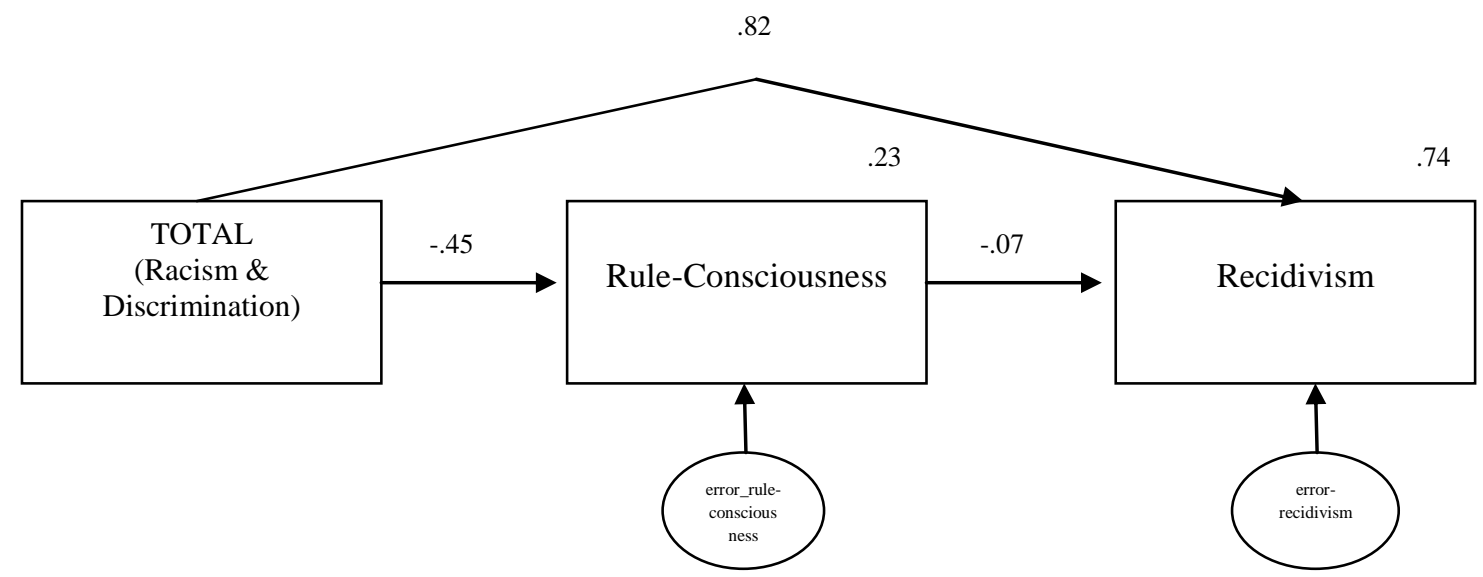

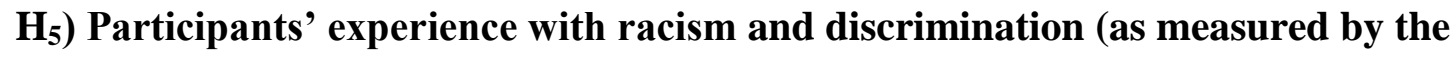
IMABI) will lead to the development of poor self-control resulting in increased incidences of repeat offending. 
To determine the effects of racism and discrimination on personality and subsequent offending, a structural equation model measuring the personality trait, selfcontrol, was generated. Racism and discrimination predicted insignificant change in the trait self-control $\left(m_{l}=.08\right)$ and self-control then subsequently predicted minimal change in recidivism $\left(m_{2}=.04\right)$. This model concludes that there is a weak relationship between racism and discrimination and the trait rule-consciousness $\left(r_{l}=.01\right)$ but a strong relationship between racism and discrimination and recidivism with self-control as an indirect mediating variable $\left(r_{2}=.74\right)$. Additionally, this model demonstrates that there is a direct relationship between racism and discrimination with recidivism $\left(r_{3}=.85\right)$ whereby the self-control personality trait indirectly affects this relationship. Statistical significance of the model varies depending on the measurements used. RMSEA (.66) and the $\chi^{2}-$ distribution were significant $(\mathrm{CMIN}=.000)$ which concludes that this model was nonsignificant; however, the comparative field index was >.90 (CFI=1.0) and that concludes that there is some statistical significance in this model.

Figure 6. Structural Equation Model: Self-Control

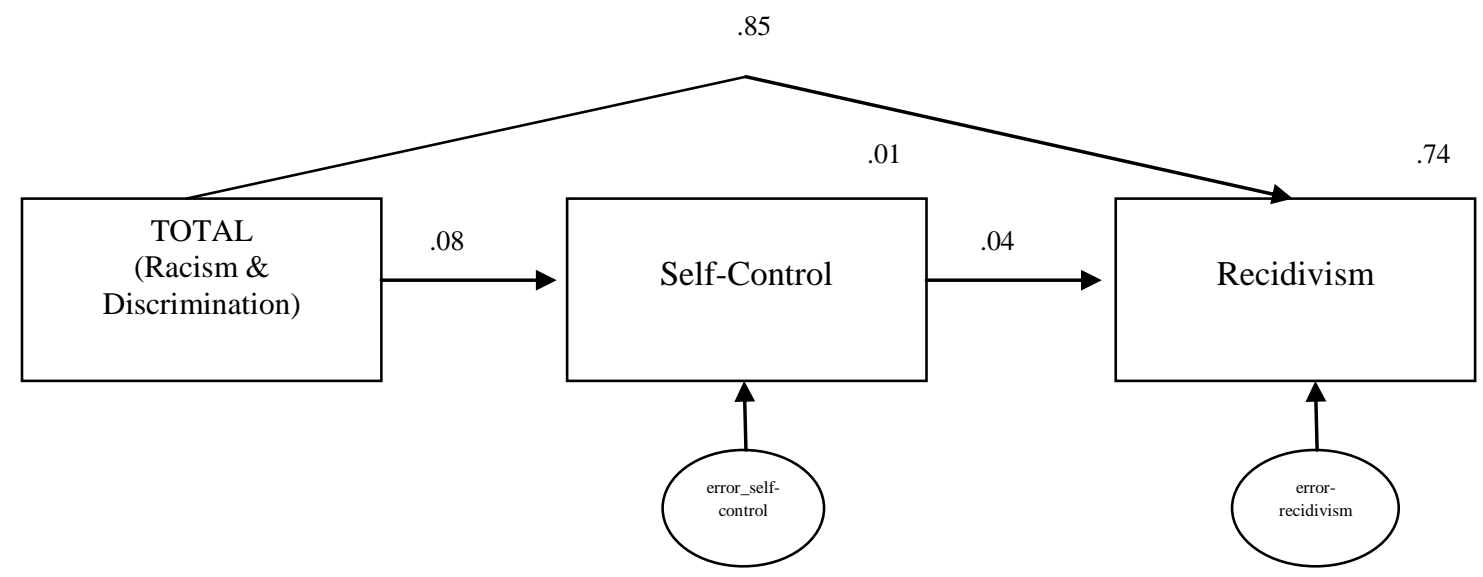




\section{CHAPTER V}

\section{Discussion}

After reviewing the current literature, several hypotheses were generated about the effects of racism and discrimination and personality development and subsequent recidivism. These five hypotheses posited that racism and discrimination had a direct effect on recidivism while indirectly being affected by a number of personality traits (warmth, dominance, vigilance, rule-consciousness, and self-control). The first hypothesis was that participants' experience with racism and discrimination would lead to the development of low warmth and subsequently lead to increased rates of recidivism. The second hypothesis stated that participants' experience with racism and discrimination would lead to the development of excessive dominance and subsequently lead to increased rates of repeat offending. The third hypothesis was that participants' experience with racism and discrimination would lead to the development of hypervigilance and subsequently lead to increased rates of recidivism. The fourth hypothesis asserted that participants' experience with racism and discrimination would lead to the development of low rule-consciousness and subsequently lead to increased rates of repeat offending. The final hypothesis was that participants' experience with racism and discrimination would lead to the development of low self-control and subsequently lead to increased rates of recidivism. All five hypotheses were partially supported by the models in this study.

Original predictions for this study were that increased experiences with racism and discrimination directly impacted one's personality and consequently influenced the likelihood that they would recidivate more often. However, each model provided contradicting results regarding the statistical significance. Warmth did relate to probation 
in the predicted negative direction but did not significantly predict higher rates of recidivism; however, measuring racism and discrimination with warmth as an indirect variable did lead to a statistically significant effect on recidivism. Dominance, however, did not relate to recidivism in the predicted direction and subsequently did not significantly predict higher rates of recidivism; however, measuring racism and discrimination with dominance as an indirect variable did lead to a statistically significant effect on recidivism in the predicted direction. Vigilance did relate to probation in the predicted direction and but did not significantly predict higher rates of recidivism; moreover, measuring racism and discrimination with vigilance as an indirect variable also did not lead to a statistically significant effect on recidivism in the predicted direction. Rule-consciousness did relate to probation in the predicted negative direction but did not significantly predict higher rates of recidivism; however, measuring racism and discrimination with rule-consciousness as an indirect variable did lead to a statistically significant effect on recidivism. Self-control did not relate to probation in the predicted negative direction nor did self-control significantly predict higher rates of recidivism; however, measuring racism and discrimination with self-control as an indirect variable did lead to a statistically significant effect on recidivism.

While each model proved to have some statistically significant findings, the results indicate that the models are not that strong. Because there were no degrees of freedom as indicated in the data set, the data fits the individual models very well. While most of the correlations between the racism and discrimination and the various personality traits were moderately significant, the relationships between the personality traits and recidivism were all statistically nonsignificant. Consequently, the direct path 
between racism and discrimination and probation were statistically significant in all of the proposed models. Therefore, there appears to be a lot of unexplained errors in the models which concludes that there is still disagreement between the current models and the data.

Reviewing the findings collectively, the results present evidence that there is a direct relationship between racism and discrimination with criminal recidivism. However, this relationship is only statistically significant when taking into account the various personality traits that indirectly impact this relationship. The personality traits that appear to significantly affect the relationship between racism and discrimination and probation are warmth, dominance, rule-consciouness, and self-control. These findings are mostly congruent with previous research related to personality and criminal activity. The relationship between low self-control and crime continues to exist (Pratt \& Cullen, 2000) proving that self-control is in fact a strong link to crime. Additionally, these findings connect to research about the residual effects of excessive dominance on crime (Mitchell \& MacKenzie, 2006) as a result of increased egocentricity and difficulty complying with the confinement of incarceration. However, these findings do not support previous research about the impact of hypervigilance and crime; studies provide a variety of reasons as to why hypervigilant individuals are more likely to commit crimes such as a desire to protect oneself from being victimized (Norris \& Kaniasty, 1992). These varied findings could be a result of this population not understanding how racism and discrimination impacts their increased vigilance and criminality, but instead focusing on their social environment as being the reasoning behind their hypervigilance. This research shows that there is in fact a strong relationship between racial discrimination and 
recidivism focusing on hypervigilance, and may thus provide explanation for these varied findings in this way.

\section{Limitations}

In reviewing the findings, each model proved to be fairly weak in terms of general significance and support of the hypotheses. Moreover, the models showed a high amount of unexplained error, which exemplifies continued incongruence between the models and the data. However, the data does in fact fit the model perfectly in that there are no degrees of freedom. Using a direct path in the model reduced the chi-squared distribution, which also improved the significance of the models.

The most significant limitation in this study is the fairly small sample size.

Because of the smaller sample size, the structural equation models were generated using measured variables, thus weakening the strength of the individual models. If there were more participants in the study, latent variables could have been used and the relationships between each variable would have been studied with greater depth. Because of the sample size, all of the models also had extreme RMSEA values (all >0). With a smaller sample, there is less power in a RMSEA measurement as it becomes more difficult to detect differences in the data. However, the comparative fit index, based on the average correlations between the variables in the data, all proved to be statistically significant $(\mathrm{CFI}=1)$. As a result, a larger sample size likely would have led to lower RMSEA measurements which could have led to the strengthening of the current models or an ability to explore for latent variables with an increased population.

\section{Future Directions}

Additional research on the effects of racism and discrimination on personality and 
recidivism is still needed. Because these findings show disparities in the statistical significance of the model, a study with a larger population could provide additional findings to see if there is in fact a direct causal relationship between all three variables. As this research study was racially homogenous, future research should explore the relationship between these variables using other populations such as other racial minorities, juvenile offenders, and males who are older than 25. A supplemental layer of the research could also take into account the effects of age on these findings to see if experiences with racism and discrimination differ in terms of their effects on personality traits among different age groups. Comprehensive research could also be conducted with the African American population across the country to see if there are environmental effects on racism and discrimination which might then impact personality and recidivism. A longitudinal study centered on the effects of racism and discrimination if the probationer becomes reincarcerated after completion of the study could also provide interesting findings in future research.

Such research could also explore the various programs put in place to curb the likelihood that these men will continue to engage in criminal behaviors. In Alameda County, for example, the Probation Rehabilitation Opportunities Program, or PROPS program was designed in response to Senate Bill 678 to reduce the number of state and county commitments and help probationers transition back into the community. Specifically, PROPS addresses some of the behavioral issues using clinical applications such as cognitive-behavioral therapy groups to address the participants' distortions with the purpose of reducing their maladaptive behaviors. Studying such a program could also coincide with this research to examine the effects of clinical treatment on this population. 


\section{Conclusion}

The African American community continues to be pathologized due to a variety of sociocultural differences from the dominant White culture in multiple forms of racial discrimination (Painter, 2007; Parham et al., 1999). Subsequently, the research about this population, and African American males in particular, continues to depict this community as hypercriminal due to the social demographics of their neighborhoods such as low socioeconomic status, racial backgrounds, and higher rates of single-parent households (Akbar, 1981; Painter, 2007; Russell, 1998; Wright \& Younts, 2009). However, the dearth in the current research on this population presented an area of study to explore individual factors that may account for the disproportionate percentages of African Americans in the criminal justice system.

Previous research explores the connections between racial discrimination and criminal offending and has often concluded that a positive association exists between racial discrimination and increased criminal activity (Burt, Simons \& Gibbons, 2012). This study sought to expand these findings by reviewing the effects of psychological variables such as personality traits to see if this relationship was mediated by other factors; specifically if racism and discrimination in fact lead to the development of certain traits, which in turn lead to an increased likelihood of committing criminal behaviors. This study was designed to capture this information because though racism and discrimination are an everyday experience in the lives of many African American men, these factors are rarely considered as a potential impetus for other behaviors.

By focusing on multiple personality traits, this study provides unique insight exploring how racism and discrimination may provide an additional layer to 
understanding the current psychological research. Using these variables for future research could help to explore the disproportionate percentages of African American males in the criminal justice system, aside from the sociocultural factors traditionally used in criminology research. In today's society, racism and discrimination impact how the dominant culture labels African American males as the symbolic assailant or "everyday criminal" while at the same time influencing how African American men view themselves; therefore, these assumptions are likely the biggest threat to African American men being incarcerated. In his infamous "I Have a Dream" speech, Dr. Martin Luther King Jr. (1963) proclaimed "I have a dream that my four little children will one day live in a nation where they will not be judged by the color of their skin, but by the content of their character." Fifty years later, this portion of his speech remains a distant dream for African Americans in general, but specifically in the lives of African American men who continue to be judged based on longstanding racial prejudices that equate them as criminal. Perhaps in the future, with work to decrease the occurrence of racism in the lives of racial minorities, we will see an end to this type of discrimination and related life pattern for African American men. 


\section{References}

Akbar, N. (1981). Mental disorders among African Americans. Black Books Bulletin, 7, $18-25$.

Botelho, G. (2012, May 23). What happened the night Trayvon Martin died. CNN, Retrieved from http://www.cnn.com/2012/05/18/justice/florida-teen-shootingdetails/index.html

Brewer, R. M., \& Heitzeg, N. A. (2008) The racialization of crime and punishment: Criminal justice, color-blind racism, and the political economy of the prison industrial complex. American Behavioral Scientist, 51, 625-644. doi: $10.1177 / 0002764207307745$

Brunson, R. K., \& Miller, J. (2006). Gender, race, and urban policing: The experience of African American youths. Gender and Society, 20, 531-552. doi:

$10.1177 / 0891243206287727$

Bryant, W. W. (2011). Internalized racism's association with African American male youth's propensity for violence. Journal of Black Studies, 42, 690-707. doi: 10.1177/0021934710393243.

Burt, C. H., Simons, R. L., \& Gibbons, F. X. (2012). Racial discrimination, ethnic-racial socialization, and crime: A micro-sociological model of risk and resilience. American Sociological Review, 77, 648-677. doi: 10.1177/0003122412448648

Cattell, R. B., Cattell, A. K., \& Cattell, H. E. (1993). Sixteen Personality Factor Questionnaire, Fifth Edition. Champaign, IL: Institute for Personality and Ability Testing, Inc. 
Dixon, T. L. (2008). Crime news and racialized beliefs: Understanding the relationship between local news viewing and perceptions of African Americans and crime. Journal of Communication, 58, 106-125. doi: 10.1111/j.1460-2466.2007.00376.x

Dixon, T. L., \& Azocar, C. L. (2007). Priming crime and activating blackness: Understanding the psychological impact of the overrepresentation of blacks as lawbreakers on television news. Journal of Communication, 57, 229-253. doi: 10.1111/j.1460-2466.2007.00341.x

Federal Bureau of Prisons. (2012). Quick facts about the bureau of prisons. Retrieved February 12, 2012, from the Federal Bureau of Prisons Web site: http://www.bop.gov/news/quick.jsp\#.

Ferguson, A. A. (2000). Bad boys: Public schools in the making of black masculinity. Ann Arbor: University of Michigan Press.

Fox, J. A., \& Swatt, M. L. (2008). The recent surge in homicides involving young black males and guns: Time to reinvest in prevention and crime control. Retrieved February 2, 2012, from http://blackstonian.com/news/2011/03/the-recent-surgein-homicides-involving-young-black-males-and-guns/.

Friedman, W., Lurigio, A. J., Greenleaf, R., \& Albertson, S. (2004). Encounters between police officers and youths: The social costs of disrespect. Journal of Crime and Justice 27, 1-25.

Gottfredson, M. R., \& Hirschi, T. (1990). A general theory of crime. Stanford, CA: Stanford University Press.

Hay, C., \& Forrest, W. (2006). The development of self-control: Examining self-control theory's stability thesis. Criminology, 44, 739-774. 
Heyman, D., Brown, G., Bigwood, J., Moritz, N.H., Frankfurt, P., Holmes, P.L., McDaniels, R. (Producers) \& Dickerson, E.R. (Director). (1992). Juice [Motion Picture]. United States: Paramount Pictures.

Hirschi, T., \& Gottfredson, M. G. (2001). Self-control theory. In R. Paternoster, \& R. Bachman (Eds.), Explaining criminals and crime (pp. 81-96). Los Angeles: Roxbury.

Hughes, A., \& Hughes, A. (Directors and Executive Producers). (1993). Menace II Society [Motion Picture]. United States of America: New Line Cinema.

Jonsson, P. (2012, May 1). Stand your ground law: Florida review panel to draw wide scrutiny. The Christian Science Monitor. Retrieved from http://www.csmonitor.com/USA/Justice/2012/0501/Stand-Your-Ground-lawFlorida-review-panel-to-draw-wide-scrutiny.

King, M.L.K. (1963). I have a dream... (Speech at the March on Washington). Retrieved from National Archives and Records Administration website: http://www.archives.gov/press/exhibits/dream-speech.pdf

Mauer, M., \& Chesney-Lind, M. (Eds.). (2002). Invisible punishment: The collateral consequences of mass imprisonment. New York: New Press.

Mercer, S. H., Ziegler-Hill, V., Wallace, M., \& Hayes, D. M. (2011). Development and initial validation of the inventory of microaggressions against Black individuals. Journal of Counseling Psychology, 58, 457-469.

Mio, J. S., Barker, L. A., \& Tumambing, J. (2009). Multiculutral psychology: Understanding our diverse communities. New York: McGraw Hill 
Mitchell, O., \& MacKenzie, D. L. (2006). The stability and resiliency of self-control in a sample of incarcerated offenders. Crime and Delinquency, 52, 432-449. doi: $10.1177 / 0011128705280586$

Mooradian, J.K. (2010). Breaking the lock: Addressing 'disproportionate minority confinement' in the United States using a human rights approach. Journal of Social Work, 12, 37-50. doi: 10.1177/146801731030087

Norris, F. H. \& Kaniasty, K. (1992). A longitudinal study of the effects of various crime prevention strategies on criminal victimization, fear of crime, and psychological distress. American Journal of Community Psychology, 20, 625-648.

Painter, N. I. (2007). Creating black Americans. New York: Oxford University Press.

Parham, T. A., White, J. L., \& Ajamu, A. (1999). The Psychology of blacks. Upper Saddle River, New Jersey: Prentice Hall.

Pratt, T. C., \& Cullen, F. T. (2000). The empirical status of Gottfredson and Hirschi's general theory of crime: A meta-analysis. Criminology, 38, 931-964.

Radosh, P. F. (2008). War on drugs: Gender and race inequities in crime-control strategies. Criminal Justice Studies, 21, 167-178. doi: 10.1080/14786010802159830.

Reiman, J. (1996). ...And the poor get prison: Economic bias in American criminal justice. Needleman Heights, Massachusetts: Allyn \& Bacon.

Roberts, D. E. (2004). The social and moral cost of mass incarceration in African American communities. Stanford Law Review, 56, 1271-1305.

Russell, K. (1998). The color of crime. New York: New York University Press. 
Russell, M., \& Karol, D. (2002). The 16PF fifth edition administrator's manual with updated norms. Champaign, IL: Institute for Personality and Ability Testing, Inc.

Saucier, D. A., Hockett, J. H., \& Wallenberg, A. S. (2008). The impact of racial slurs and racism on the perceptions and punishment of violent crime. Journal of Interpersonal Violence, 23, 685-701.

Saucier, D. A., Hockett, J. M., Zanotti, D. C., \& Heffel, S. (2010) Effects of racism on perceptions and punishment of intra- and interracial crimes. Journal of Interpersonal Violence, 25, 1767-1785. doi: 10.1177/0886260509358386

Sue, D. W. (1978). Eliminating cultural oppression in counseling: Toward a general theory. Journal of Counseling Psychology, 25, 419-428.

Sue, D. W. (2010). Microaggressions in everyday life: Race, gender, and sexual orientation. New Jersey: John Wiley \& Sons.

Sue, D.W., Capodilupo, C.M., Torino, G.C., Bucceri, J.M., Holder, A.M.B., Nadal, K.L., \& Esquilin, M. (2007). Racial microaggressions in everyday life: Implications for clinical practice. American Psychologist, 62, 271-286. doi: 10.1037/0003066X.62.4.271

Sutherland, E. H. \& Cressey, D. R. (1974). Criminology. 9th ed. Philadelphia: Lippincott. United States Census Bureau. (2012). State and county quick facts. Retrieved February 12, 2012, from http:/quickfacts.census.gov/qfd/states/00000.html.

U.S. Department of Justice, Bureau of Justice Statistics. (2011). Probation and parole in the United States, 2010 (BJS Publication No. 236019) Retrieved from http://bjs.ojp.usdoj.gov/content/pub/pdf/ppus10.pdf 
Wacquant, L. (2002) 'From slavery to mass incarceration: rethinking the 'race question' in the U.S." New Left Review, 13.

Williams, J. S., Singh, B. K., \& Singh, B. B. (1994). Urban youth, fear of crime, and resulting defensive actions. Adolescence, 29, 323-330.

Williams, N.H. (2010) "Where are the men?: The impact of incarceration and re-entry on African-American men and their children and families." Retrieved from Community Voices website:

http://www.communityvoices.org/uploads/wherearethemen2_00108_00144.pdf

Wright, B. R. E., \& Younts, C. W. (2009). Reconsidering the relationship between race and crime: Positive and negative predictors of crime among African American youth. Journal of Research in Crime and Delinquency, 46, 327-352. doi: 10.1177/00224278099335170. 


\section{Appendix A}

\section{Demographics Form}

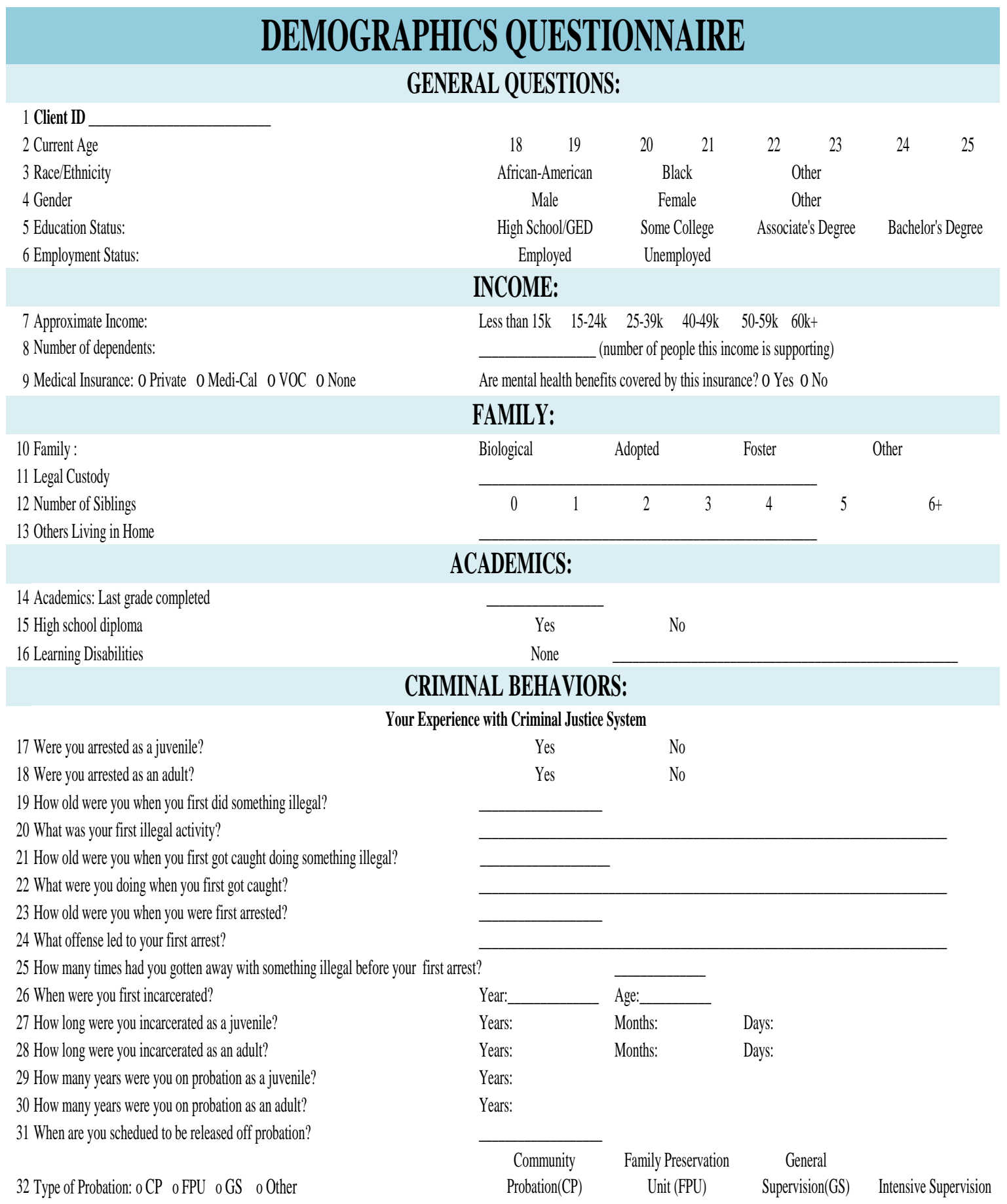




\section{Appendix B}

\section{Survey for Participation}

1. What was your earliest involvement with the criminal justice system?

2. How do you view crime?

3. Do you believe that the criminal justice system is fair? $\quad \mathrm{Y} \quad \mathrm{N}$

4. Do you believe that your sentence was fair? $\quad$ Y $\quad \mathrm{N}$

5. Do you think crime is a viable option for your life? $\quad$ Y $\quad \mathrm{N}$

6. Do you think the system is fair against African Americans? $\quad \mathrm{Y} \quad \mathrm{N}$

7. Do you feel singled out by law enforcement in your community? $\quad \mathrm{Y} \quad \mathrm{N}$

8. As a male, do you feel that African American women are treated better by the $\begin{array}{lll}\text { criminal justice system? } & \mathrm{Y} & \mathrm{N}\end{array}$

9. Do you believe that other races are treated better by the criminal justice system?

(i.e. Whites, Asians, Latinos, etc.) $\quad \mathrm{Y} \quad \mathrm{N}$

10. Where has your incarceration been? (i.e. local jail, state prison, or both)

County Jail
State Prison

Both 


\section{Appendix C}

Inventory of Microaggressions Against Black Individuals (IMABI)

(Mercer, Ziegler-Hill, Wallace, \& Hayes, 2011)

Instructions: Events that sometimes occur in the lives of students are listed below. Please read each event carefully. Indicate whether you have experienced each event DURING THE LAST YEAR and how much the event upset you if you experienced it. Please respond using the following scale:

$$
\begin{aligned}
& 0 \text { - This has NEVER HAPPENED TO ME } \\
& 1 \text { - This event happened but I was NOT UPSET } \\
& 2 \text { - This event happened and I was SLIGHTLY UPSET } \\
& 3 \text { - This event happened and I was MODERATELY UPSET } \\
& 4 \text { - This event happened and I was EXTREMELY UPSET }
\end{aligned}
$$

1. I was made to feel that my achievements were primarily due to preferential treatment based on my racial/ethnic background.

2. I was treated like I was of inferior status because of my racial/ethnic background.

3. I was treated as if I was a potential criminal because of my racial/ethnic background.

4. I was made to feel as if the cultural values of another race/ethnic group were better than my own.

5. Someone told me that I am not like other people of my racial/ethnic background. 6. Someone made a statement to me that they are not racist or prejudiced because they have friends from different racial/ethnic backgrounds.

7. I was made to feel like I was talking too much about my racial/ethnic background. 8. When successful, I felt like people were surprised that someone of my racial/ethnic background could succeed.

9. Someone assumed I was a service worker or laborer because of my race/ethnicity. 10. I was followed in a store due to my race/ethnicity.

11. Someone reacted negatively to the way I dress because of my racial/ethnic background.

12. Someone asked my opinion as a representative of my race/ethnicity.

13. Someone told me that they are not racist or prejudiced even though their behavior suggests that they might be.

14. Someone told me that everyone can get ahead if they work hard when I described a difficulty related to my racial/ethnic background.

Note. All items are keyed in a positive direction such that higher scores reflect more experiences concerning microaggressions. The authors grant other researchers permission to use this measure. 